\title{
Assessing Impacts of the High-Frequency Assimilation of Surface Observations for the Forecast of Convection Initiation on 3 April 2014 within the Dallas-Fort Worth Test Bed
}

\author{
NiCHOLAS A. GASPERONI \\ School of Meteorology, and Center for Analysis and Prediction of Storms, University of Oklahoma, \\ Norman, Oklahoma \\ XUGUANG WANG \\ School of Meteorology, University of Oklahoma, Norman, Oklahoma \\ KEITH A. BREWSTER \\ Center for Analysis and Prediction of Storms, University of Oklahoma, Norman, Oklahoma \\ FREDERICK H. CARR \\ School of Meteorology, and Center for Analysis and Prediction of Storms, \\ University of Oklahoma, Norman, Oklahoma
}

(Manuscript received 16 May 2018, in final form 6 September 2018)

\begin{abstract}
The Nationwide Network of Networks (NNoN) concept was introduced by the National Research Council to address the growing need for a national mesoscale observing system and the continued advancement toward accurate high-resolution numerical weather prediction. The research test bed known as the Dallas-Fort Worth (DFW) Urban Demonstration Network was created to experiment with many kinds of mesoscale observations that could be used in a data assimilation system. Many nonconventional observations, including Earth Networks and Citizen Weather Observer Program surface stations, are combined with conventional operational data to form the test bed network. A principal component of the NNoN effort is the quantification of observation impact from several different sources of information. In this study, the GSI-based EnKF system was used together with the WRF-ARW Model to examine impacts of observations assimilated for forecasting convection initiation (CI) in the 3 April 2014 hail storm case. Data denial experiments tested the impact of high-frequency $(5 \mathrm{~min})$ assimilation of nonconventional data on the timing and location of $\mathrm{CI}$ and subsequent storm evolution. Results showed nonconventional observations were necessary to capture details in the dryline structure causing localized enhanced convergence and leading to CI. Diagnosis of denial-minus-control fields showed the cumulative influence each observing network had on the resulting CI forecast. It was found that most of this impact came from the assimilation of thermodynamic observations in sensitive areas along the dryline gradient. Accurate metadata were found to be crucial toward the future application of nonconventional observations in high-resolution assimilation and forecast systems.
\end{abstract}

\section{Introduction}

With the increasing sophistication of data assimilation (DA) methods and accompanying numerical weather prediction (NWP) models, there is great potential to increase our understanding and forecasting accuracy of high-impact severe weather events. As operational NWP forecasts move toward grid resolutions that resolve

Corresponding author: Nicholas A. Gasperoni, ngaspero@ou.edu convection explicitly, dense observations are needed in both space and time to be able to capture the smallscale and rapidly evolving features of such severe events. A report by the U.S. National Research Council (NRC 2009) underscored the need for a national mesoscale network of observations and recommended the integration of existing and future mesoscale observations into a Nationwide Network of Networks (NNoN). The report further recommended the implementation of research test beds in order to objectively evaluate 
the impacts of proposed observing systems for the NNoN concept. Such test beds facilitate collaboration among researchers, forecasters, measurement specialists, and the private sector to accelerate the transition from research of observing systems to their operational implementation (Dabberdt et al. 2005; NRC 2009).

The Collaborative Adaptive Sensing of the Atmosphere (CASA; McLaughlin et al. 2009) Dallas-Fort Worth (DFW) Urban Demonstration Network (hereafter DFW test bed) was established as a test bed to carry out the vision of the NNoN concept (NRC 2012). Many in situ surface and remote sensing observation systems have been implemented for the DFW test bed. Surface observing networks include Earth Networks surface stations (ERNET; Earth Networks 2017), amateur stations from the Citizen Weather Observer Program (CWOP; Chadwick 2014), truck-mounted observations from the Mobile Platform Environmental Data Network (MoPED; Heppner 2013), and weather stations operated by Understory Weather (2015). Remote sensing observations include seven X-band radars operated by CASA, two SODARs operated by WeatherFlow (2017), and three microwave radiometers supplied by Radiometrics in partnership with Earth Networks (Bosse et al. 2012). One important goal of the DFW test bed is to measure the impacts from each of these observing systems in robust state-of-the-art DA and forecasting systems.

Quantification of forecast impact from different real observational systems is traditionally done through observing system experiments (OSEs). There is an everexpanding array of OSE-related research encompassing a wide variety of subtopics in NWP forecasting. The first OSEs were used to test the impact of mainly satellite and upper-air data on forecasts of synoptic systems with global models (e.g., Andersson et al. 1991; Zapotocny et al. 2002, 2007). With the increase in computing power and expanding use of observation networks, more recent OSEs tested data impacts using more sophisticated hybrid DA methods (e.g., Kutty and Wang 2015) and have included impacts of assimilating GPS-derived precipitable water, mesonet observations, and wind profiler data (e.g., Benjamin et al. 2010). Other recent OSEs have focused on specific regions and weather types (e.g., Singh et al. 2014; Coniglio et al. 2016; Zhang et al. 2016). With the increasing use of regional models at convection-allowing resolutions $(\leq 4 \mathrm{~km})$, OSE studies have also focused on the effects of assimilating Doppler radar radial winds and reflectivity on high-resolution forecasts of deep convection (e.g., Schenkman et al. 2011a,b; Snook et al. 2015).

The 2009 NRC report noted that the highest observational need is measurements of the planetary boundary layer (PBL), the lowest part of the atmosphere directly affected by the surface of Earth (NRC 2009). Many mesoscale features are prominently featured in the PBL, including horizontal convective rolls, surface boundaries such as drylines and fronts, and other gradients and diurnal variations influenced by topography. While radar data provide crucial measurements of ongoing precipitating systems, the current network of S-band radars overshoots a large part of the PBL. Additionally, radar data do not directly measure temperature or moisture, so important features that may trigger or maintain convection are missed, such as areas of enhanced moisture convergence or location and strength of cold pools. For these reasons, recent high-resolution DA studies have placed increasing emphasis on the assimilation of mesonet observations in addition to radar data (e.g., Carlaw et al. 2015; Johnson et al. 2015; Snook et al. 2015; Chen et al. 2016). Despite positive results, surface observations remain an operationally underutilized dataset, partly due to mismatches between coarse model terrain and actual observation heights (e.g., Ancell et al. 2011; Pu et al. 2013) and other concerns about siting and instrument quality.

One fundamental limitation of radar data is the inability to measure preconvective environments and features that lead to convection initiation (CI). Given a favorable large-scale environment, variations on the order of $1 \mathrm{~g} \mathrm{~kg}^{-1}$ of specific humidity have a large influence on the existence and location of CI, owing to small-scale features in the PBL such as dryline bulges and convective rolls (Weckwerth 2000; Weckwerth and Parsons 2006). Madaus and Hakim (2016) studied observable surface anomalies preceding isolated CI and found that warm 2-m temperature anomalies were present $90-170 \mathrm{~min}$ prior to precipitation, with detectable anomalies in moisture, wind, and pressure up to $60 \mathrm{~min}$ prior and strong vertical correlations. Thus, the prediction of CI can be potentially improved with the utilization of mesonet surface observations, even throughout the troposphere. Xue and Martin (2006a) and Liu and Xue (2008) explored the prediction of CI of two separate cases as part of the International $\mathrm{H}_{2} \mathrm{O}$ Project (IHOP; Weckwerth et al. 2004). They performed hourly assimilation of mesonet observations in addition to special IHOP upper-air and surface observations. Xue and Martin (2006a) found moderate improvements in the CI forecast; however, Liu and Xue (2008) found mixed results, showing that reducing assimilation frequency from 1 to $3 \mathrm{~h}$ actually improved the forecast in some ways. They concluded that the worse forecast was due to a weakening of surface forcing caused by the higher-frequency DA.

Sobash and Stensrud (2015, hereafter SS15) was the first study to examine subhourly assimilation of mesonet 
observations for the prediction of CI. They assimilated mesonet observations every $5 \mathrm{~min}$ for 1,2 , and $3 \mathrm{~h}$ prior to CI using an ensemble Kalman filter (EnKF). Results showed that high-frequency assimilation of mesonet observations led to improvements in timing and placement of CI as compared to hourly assimilation experiments, with $3 \mathrm{~h}$ of 5-min cycling performing best. SS15 concluded that mesonet observations provided important information on the diurnal progression of the dryline, including important small-scale variability such as dryline surges, which helped to provide more accurate initial conditions (ICs) and forecast. Furthermore, frequent assimilation of mesonet observations helped constrain the positive moisture bias of the PBL scheme used in their study. They note, however, that frequent mesonet DA may not be as impactful in other cases where model biases are minimal or where CI is driven by more large-scale forcing rather than surface features.

More recently, Madaus and Hakim (2017) performed an OSSE study examining what spatial density of observations is necessary to capture storm-scale CI processes accurately, in the absence of strong synoptic- or mesoscale forcing. They found that skillful and reliable forecasts were produced when observations were at least $4 \mathrm{~km}$ in spatial density. Unlike SS15, they found no impact in assimilating observations earlier than $1 \mathrm{~h}$ prior to CI. This suggests that for specifically convective-scale features leading to CI, hourly assimilation no earlier than $1 \mathrm{~h}$ prior to $\mathrm{CI}$ is the minimum requirement for skillful forecasts. Another challenging area is the prediction of nocturnal CI over the Great Plains, where the low-level jet and mesoscale convective system cold pool outflow can take important roles in the process. Degelia et al. (2018) found that the best CI prediction occurred when in situ measurements were used to analyze the mesoscale environment.

Although SS15 was an important foundation in showing the benefit of frequent DA of surface mesonet observations, that work was focused on the use of mesonet data as a whole, with the predominant impacts coming over areas well covered by the Oklahoma Mesonet (McPherson et al. 2007) and West Texas Mesonet (Schroeder et al. 2005). Unfortunately, many areas such as the DFW metroplex do not have a federal- or state-supported mesonet available. To have the NNoN vision succeed for regions where there are no mesonets, we must leverage the use of nonconventional surface observations from other sources, such as the CWOP and ERNET data within the DFW test bed. A limited number of studies have explored direct impacts of assimilating these nonconventional surface observations for mesoscale analysis and forecasting (e.g., Tyndall and Horel 2013; Madaus et al. 2014;
Carlaw et al. 2015). In this work, we explore the use of nonconventional surface observing networks within the DFW area for the prediction of a CI event. In contrast to SS15, we examine impacts from different nonconventional networks individually to assess benefits and limitations from using the different systems.

The first OSE study using nonconventional data within the DFW test bed was done by Carlaw et al. (2015). They tested the utility of nonconventional surface data, specifically from CWOP and ERNET, on the forecast of a tornadic supercell that caused EF3 damage. Results showed that these nonconventional surface observations helped improve the surface analysis of low-level thermodynamic fields in an otherwise data-sparse region. This study is different from Carlaw et al. (2015) in that we are using these data to predict CI rather than as a supplement to radar data for an ongoing storm. Additionally, this study employs an ensemble-based assimilation system rather than the 3DVar used by Carlaw et al. (2015), allowing for comparisons of probabilistic forecast differences.

In section 2, we summarize the severe weather event used for this study (3 April 2014) to further detail the different observation sources available within the DFW test bed for this case. Section 3 describes the experiment setup, including model and DA configurations, and provides descriptions of data denial experiments. In section 4 , the results of the denial experiments are discussed, with a diagnosis of impacts tied to observations that led to forecast differences in ensemble CI performance. In section 5, the case study is summarized with implications for potential use of these nonconventional observations in future DA systems.

\section{Case overview: 3 April 2014}

\section{a. Summary, synoptic setup, and storm evolution}

According to the National Centers for Environmental Information (NCEI; NCDC 2014), severe storms in the Dallas area on 3 April 2014 caused an estimated $\$ 500$ million in damage, mainly in Denton County, Texas. NCEI storm reports included all types of severe weather across north Texas, including numerous hail reports, with the largest up to softball-size ( $108 \mathrm{~mm} ; 4.25 \mathrm{in}$.) diameter, a high wind report of $41 \mathrm{~m} \mathrm{~s}^{-1}(82 \mathrm{kt} ; 1 \mathrm{kt} \approx$ $0.5144 \mathrm{~m} \mathrm{~s}^{-1}$ ), and three confirmed tornadoes northeast of the DFW area causing EF0 and EF1 damage (Fig. 1).

On the synoptic scale, a high-amplitude, positively tilted short-wave trough was located over the central and southern Rockies region at 1200 UTC 3 April 2014 (Fig. 2a). The trough progressed into a neutral tilt with a region of upper-level divergence extending from northeast Texas through Oklahoma, Arkansas, and Missouri by 


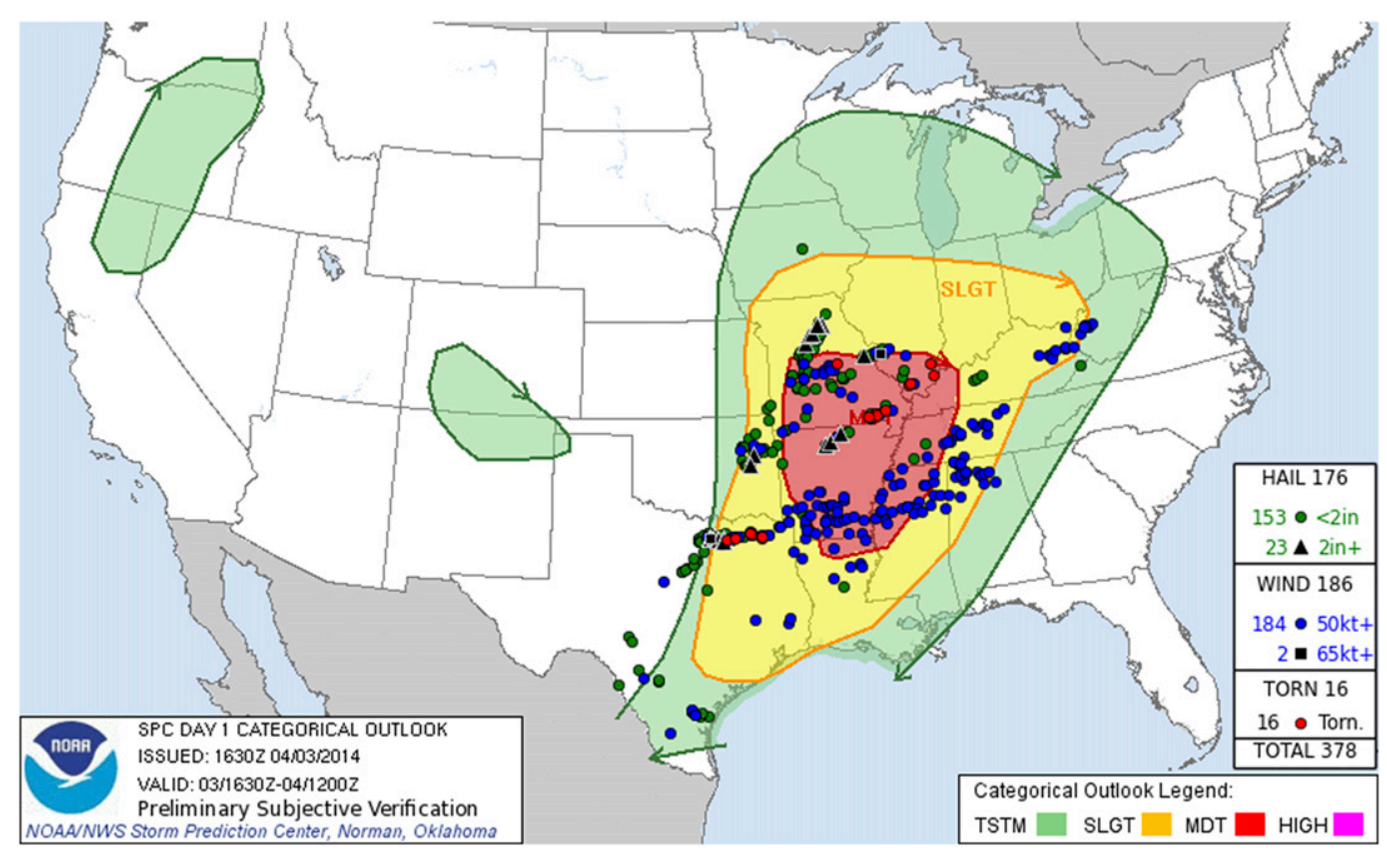

FIG. 1. SPC preliminary storm reports valid from 1200 UTC 3 Apr to 1200 UTC 4 Apr 2014, overlaid on the day 1 categorical outlook issued at 1630 UTC 3 Apr 2014. Markers indicate tornado reports (red dots), significant hail reports greater than 2-in. diameter (black triangles), other severe hail reports (green dots), significant wind reports above $65 \mathrm{kt}$ (black squares), and other severe wind reports (blue dots).

0000 UTC 4 April 2014 (Fig. 2b). In response, the associated surface low deepened and moved toward northeast Missouri by 0000 UTC 4 April. A cold front extended to the southwest through Oklahoma and the Texas Panhandle, with a dryline intersecting it over central Oklahoma and extending southwest through Texas, west of the DFW area (Fig. 3). The dryline mixed eastward through the afternoon toward the western edge of the DFW domain. The Fort Worth, Texas, radiosonde launched at 1200 UTC 3 April showed a potentially unstable atmosphere available ahead of the dryline near Dallas, with convective available potential energy (CAPE) ranging from 2800 to $3500 \mathrm{~J} \mathrm{~kg}^{-1}$ (Fig. 4). A substantial capping inversion existed, inhibiting convection from developing before 1800 UTC. As the afternoon progressed, the cloud layer just east of the dryline near Dallas cleared and moved east (Fig. 3), allowing for the solar insolation necessary to erode the capping inversion and result in conditions favorable for CI.

The first CI event appears at 1820 UTC in southwest Wise County, Texas (Fig. 5a). As this storm grows and moves northeast, a second storm initiates at approximately 1900 UTC approximately $25 \mathrm{~km}$ to the southwest of the first CI event (Fig. 5b). Both storms develop into strong hail-producing supercells as they travel through the north side of the DFW test bed (Fig. 5c). The second storm tracks through Denton, Texas, around 2030 UTC, producing very large hail up to $100 \mathrm{~mm}$ around $2045 \mathrm{UTC}$ (Fig. 5d). Other areas of CI occur outside of the DFW area, including a cell along the northern border of Comanche County, Texas, around 2000 UTC (Fig. 5c) and additional locations south and southwest between 2100 and 2200 UTC, though these storms are generally not as well organized (Fig. 5e). Additional storm development occurs after 2200 UTC, eventually producing the weak tornadoes northeast of the DFW area. This study will focus primarily on the first CI events that occur between 1800 and 1900 UTC, as these storms are responsible for producing the damaging severe hail in Denton County. Additionally, with no preexisting storms nearby, the CI process for these specific storms may be more clearly explored. Hail report locations are shown for 1800-2200 UTC 3 April 2014 in Fig. 5f. These reports were taken from NCDC (2014) as well as the Meteorological Phenomena Identification near the Ground (mPING; Elmore et al. 2014) project; mPING observations use crowdsourcing to provide observations of precipitation type across the United States. Hail is reported from eastern Wise County through Denton County and to the northeast.

\section{b. Description of observations used}

The DFW test bed is a medley of many observational platforms, summarized in Table 1. Observing systems are separated into two categories: conventional and nonconventional. Here, conventional data 


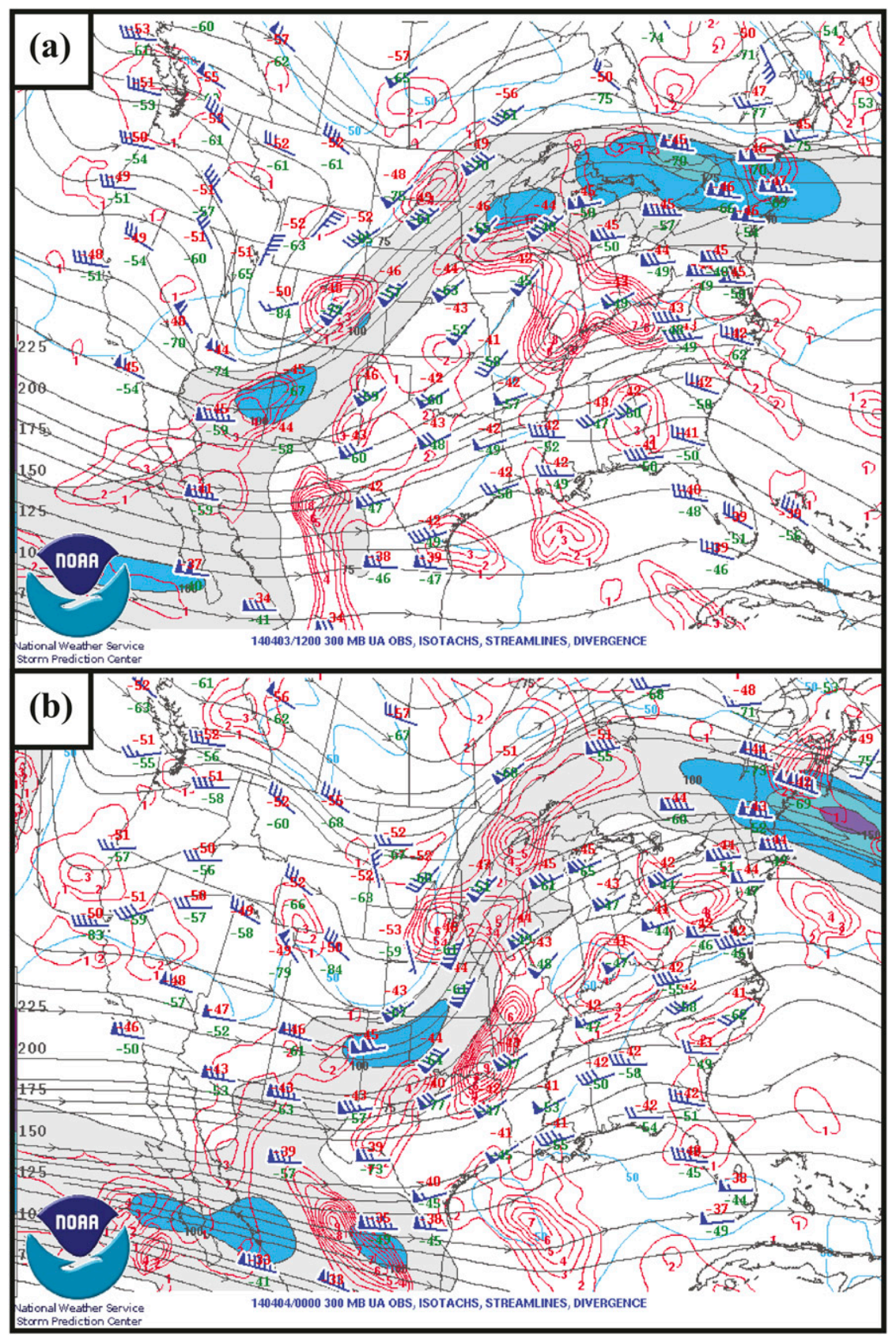

FIG. 2. Upper-air 300-hPa observations, isotachs (blue and color-filled contours), streamlines (black contours), and divergence (red contours) valid at (a) 1200 UTC 3 Apr and (b) 0000 UTC 4 Apr 2014.

refers to observations that are already typically used in operational data assimilation systems. They include upper-air soundings, wind profilers, aircraft data from the Aircraft Communications Addressing and Reporting System (ACARS; Moninger et al. 2003), surface data from Automated Surface Observing System (ASOS) and Automated Weather Observing System (AWOS), and integrated water vapor data from global positioning satellite precipitable water vapor
(GPS PWV) observations. In this study, we also consider the Oklahoma and West Texas Mesonets to be conventional datasets with quality similar to ASOS and AWOS. Additionally, radar data from the Next Generation Weather Radar (NEXRAD) network of WSR-88D S-band radars are used as a conventional data source. Nonconventional data are all the other sources that are not yet fully implemented in operational DA systems. For radar, these include seven low-cost CASA X-band 


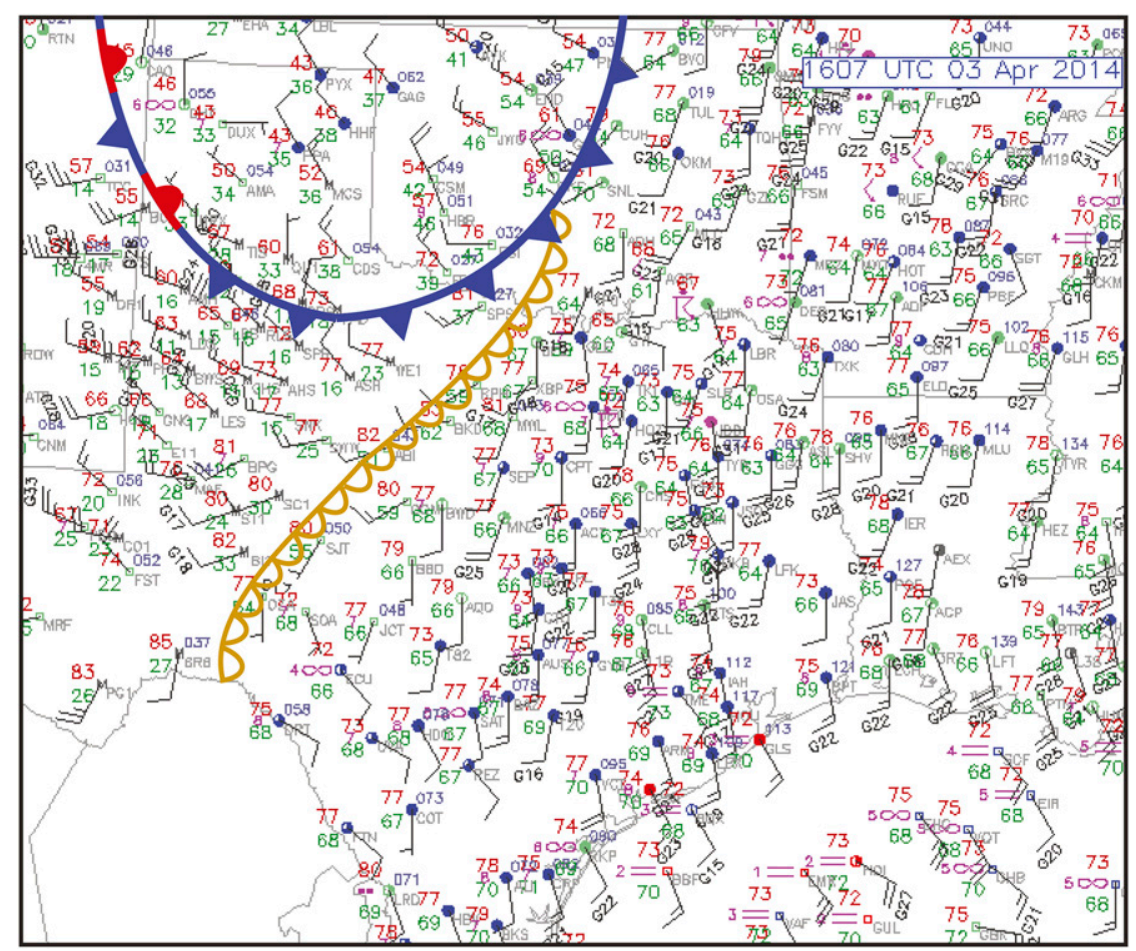

FIG. 3. Surface map of observations with approximate locations of cold front (blue line with triangles), stationary front (mixture of blue triangles and red scallops), and dryline (brown scalloped line) valid 1607 UTC 3 Apr 2014.

radars deployed in the DFW test bed, as well as C-band Terminal Doppler Weather Radars (TDWRs) available at major airports.

Nonconventional surface observations include CWOP, ERNET, and MoPED. CWOP data come from a volunteer group who transmit weather data using the Automatic Position Reporting System as a Weather Network (APRSWXNET; Chadwick 2014). These observations are found near volunteers' homes, backyards, and businesses. They are ingested into the Meteorological Assimilation Data Ingest System (MADIS) and subject to the same quality control checks as other datasets within MADIS (Miller et al. 2005). ERNET is a network of over 8000 surface observations across the country, initially installed near public schools and buildings for real-time weather data used during television broadcasts. These data are also ingested via MADIS and available for experiments within the test bed. Both CWOP and ERNET were installed without enforcing siting standards that ASOS and AWOS employ. As such, they may exhibit additional representativeness errors and biases, such as the low wind speed bias noted by Carlaw et al. (2015). MoPED data are weather sensors mounted on trucking fleets. Global Science and Technology (GST) started the program in 2009 in partnership with NOAA and the National Mesonet Program (Dahlia 2013). These sensors provide measurements of pressure, temperature, humidity, and precipitation. There are a few other nonconventional mesonet-type observations within the MADIS dataset that are separate from any previously mentioned. These observations are still used during the assimilation procedure described in the next section; however, they are not a primary focus of this study, so they have been separated into a miscellaneous nonconventional category. ${ }^{1}$

\section{Experiment setup}

\section{a. Model configurations and initial ensemble}

The model chosen for this study is the Weather Research and Forecasting (WRF) Model, specifically version 3.7 of the Advanced Research WRF (ARW)

\footnotetext{
${ }^{1}$ A comprehensive list of mesonet data providers within MADIS can be found at http://madis.noaa.gov/mesonet_providers.html. In and near the DFW test bed, these observations include AIRNow (www.airnow.gov), HADS2 hydrometeorological observations (http://hads.ncep.noaa.gov/WhatIsHADS.html), observations gathered from the MesoWest cooperative mesonet project (https:// mesowest.utah.edu), Remote Automated Weather Stations (RAWS; https://raws.nifc.gov), GPS-Met (https://madis.noaa.gov/madis_gpsmet. shtml), and Lower Colorado River Authority (LCRA) Hydromet observations (https://hydromet.lcra.org).
} 


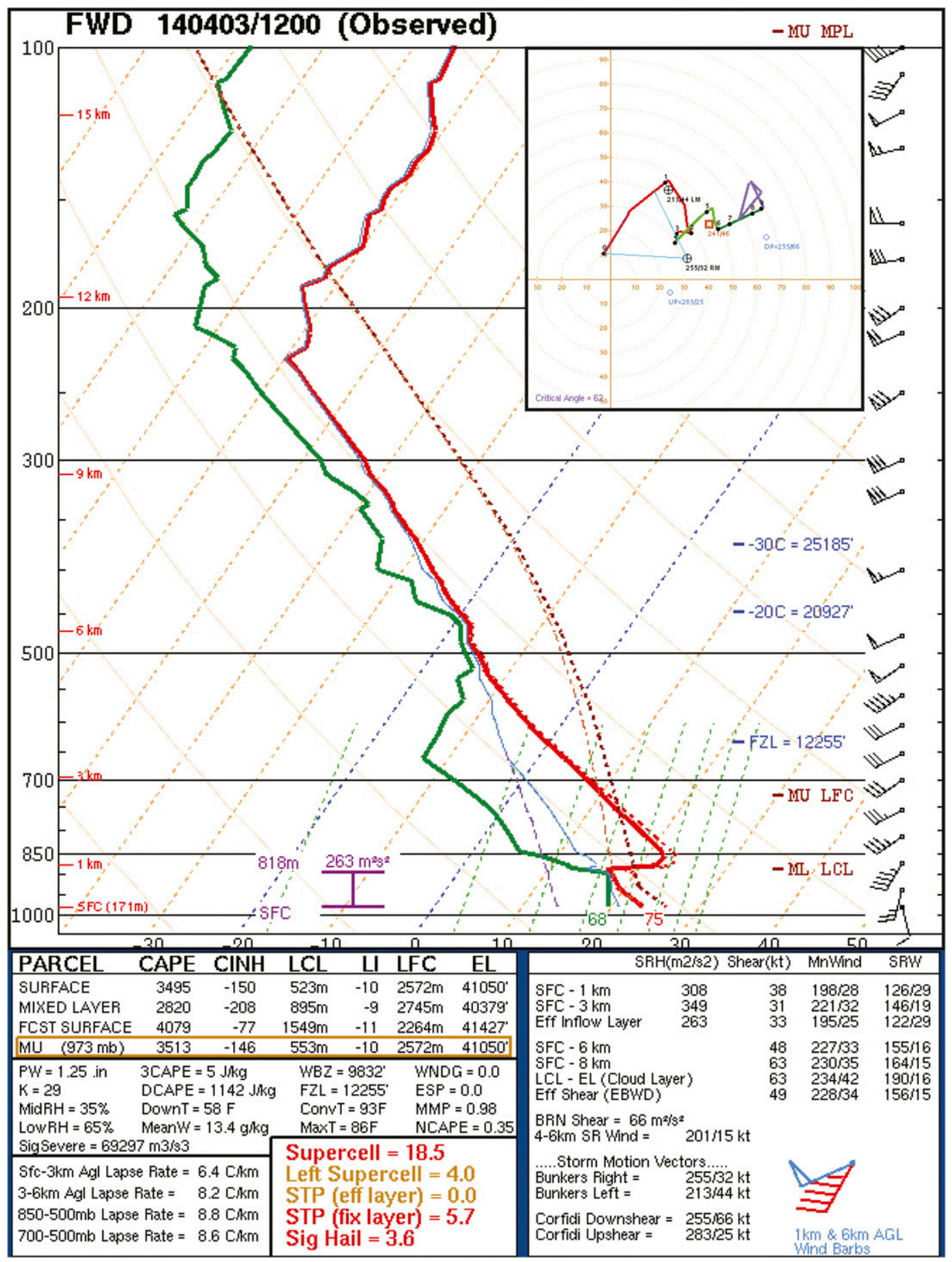

FIG. 4. Fort Worth, TX (FWD), sounding and hodograph (upper-right corner) valid 1200 UTC 3 Apr 2014, taken from the SPC Experimental Sounding Analysis System, which uses sounding analysis program NSHARP (Thompson and Hart 2017).

core (Skamarock and Klemp 2008). The ensemble used here was initialized from a combination of ensemble members from other systems, shown in Table 2. The ensemble IC was provided by interpolating each ensemble member at 0300 UTC 3 April 2014 to the $12-\mathrm{km}$ outer grid centered over north Oklahoma (Fig. 6). The inner grid has 2.4-km horizontal grid spacing, centered over the DFW 


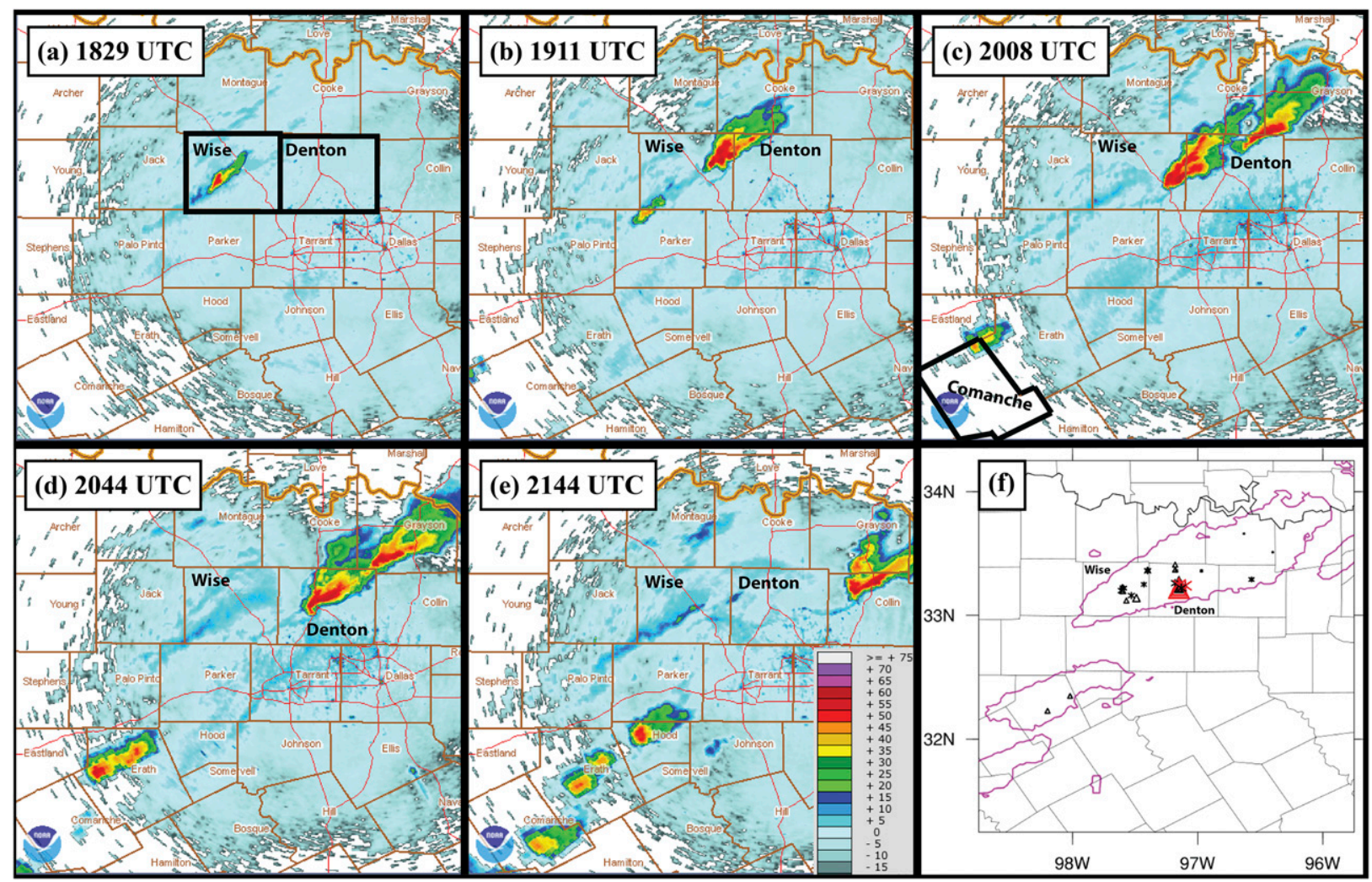

FIG. 5. (a)-(e) Observed digital hybrid reflectivity from terminal Doppler radar TDAL, valid at 1829, 1911, 2008, 2044, and 2144 UTC, respectively. (f) SPC severe hail reports (triangles) and mPING hail reports (asterisks) between 1800 and 2200 UTC. Red markers indicate significant hail reports greater than $2 \mathrm{in}$., and magenta lines indicate the 30-dB $Z$ contour of maximum observed composite reflectivity over the 1800-2200 UTC time period.

test bed. This grid is initialized at 1500 UTC 3 April 2014 using two-way nesting within the WRF. Prior to any DA on the inner grid, an hour of model integration was performed to allow the model to spin up the small-scale processes that can be resolved on the 2.4-km grid (Fig. 7).

Table 2 summarizes the different model settings for the WRF, including all parameterization schemes used for the outer and inner grids. Cumulus parameterization is only used on the outer grid, with four schemes evenly mixed throughout the ensemble, similar to that done by Johnson and Wang (2017). The Mellor-Yamada-Nakanishi-Niino (MYNN) PBL scheme was chosen in part based on results from Coniglio et al. (2013), who found that the MYNN scheme is approximately unbiased when verified against sounding observations in terms of PBL depth, potential temperature, and moisture. The MYNN scheme was unique among local schemes, as others tended to produce too shallow and moist PBLs. The Thompson microphysics scheme in combination with the MYNN PBL scheme produced forecasts with storm mode most closely matching reality for the case study here.

\section{b. Data assimilation settings}

The DA system chosen for this study is the Gridpoint Statistical Interpolation analysis system (GSI)-based EnKF extended to directly assimilate radar observations (Johnson et al. 2015; Wang and Wang 2017). The GSI-based EnKF uses the ensemble square root filter (EnSRF) introduced by Whitaker and Hamill (2002). On the outer domain, following a 3-h spinup forecast period, four 3-hourly cycles were performed at 0600 , 0900, 1200, and 1500 UTC using conventional observations except radar to better simulate the mesoscale environment (Fig. 7). For these analyses, first guess at appropriate time (FGAT; e.g., Massart et al. 2010) was used with model first-guess fields output every $30 \mathrm{~min}$ until the end of the DA cycling window $(1.5 \mathrm{~h}$ after analysis time). Observations within the 3-h window are then compared to a first-guess field that has been linearly interpolated in time from the nearest 30-min output to the observation time. On the inner grid, 5-min 
TABLE 1. All observing platforms available within the DFW test bed as of 2017. "Used" column represents whether that observation platform was used in this study (Y) or not (N); N/A means "not available for this study." The last column specifies whether the platform is considered a "conventional" or "nonconventional" dataset.

\begin{tabular}{|c|c|c|c|c|}
\hline Observation & Type & Provider & Used? & $\begin{array}{c}\text { Conventional (C) or } \\
\text { nonconventional (NC)? }\end{array}$ \\
\hline NEXRAD & S-band radar & NWS & $\mathrm{Y}$ & $\mathrm{C}$ \\
\hline TDWR & C-band radar & FAA & $\mathrm{N}$ & $\mathrm{NC}$ \\
\hline CASA & $\mathrm{X}$-band radar & CASA & $\mathrm{N}$ & $\mathrm{NC}$ \\
\hline MDCRS/ACARS & Aircraft & Airlines via MDCRS/ACARS & $\mathrm{Y}$ & $\mathrm{C}$ \\
\hline Radiosonde & Weather balloon & NWS & $\mathrm{Y}$ & $\mathrm{C}$ \\
\hline NOAA Profiler Network & Wind profiler & NOAA & $\mathrm{Y}$ & $\mathrm{C}$ \\
\hline GPS PWV & Precipitable water vapor & Suominet & $\mathrm{Y}$ & $\mathrm{C}$ \\
\hline ASOS/AWOS & Surface & NWS and FAA & $\mathrm{Y}$ & $\mathrm{C}$ \\
\hline Oklahoma Mesonet & Surface & Oklahoma Climatological Survey & $\mathrm{Y}$ & $\mathrm{C}$ \\
\hline West Texas Mesonet & Surface & Texas Tech University & $\mathrm{Y}$ & $\mathrm{C}$ \\
\hline CWOP & Surface & NWS & $\mathrm{Y}$ & $\mathrm{NC}$ \\
\hline ERNET & Surface & Earth Networks & $\mathrm{Y}$ & $\mathrm{NC}$ \\
\hline Understory & Surface and hail & Understory & $\mathrm{N}(\mathrm{N} / \mathrm{A})$ & $\mathrm{NC}$ \\
\hline Other mesonet & Surface & Miscellaneous federal/state agencies & $\mathrm{Y}$ & $\mathrm{NC}$ \\
\hline MoPED & Surface & GST & $\mathrm{Y}$ & $\mathrm{NC}$ \\
\hline SODAR & Wind profile & WeatherFlow & $\mathrm{N}(\mathrm{N} / \mathrm{A})$ & $\mathrm{NC}$ \\
\hline Radiometer & Thermodynamic profile & Radiometrics via Earth Networks & $\mathrm{N}$ & $\mathrm{NC}$ \\
\hline
\end{tabular}

cycling is used to capture rapidly evolving storm-scale structures within the DA system. In addition to conventional observations, nonconventional surface observations and NEXRAD radar radial velocity and reflectivity are also assimilated on the inner grid.

The purpose of the radar DA is to capture existing convection within the 1600-1800 UTC time period and eliminate any spurious convection that develops within the model. Both precipitation and clear-air reflectivity observations are assimilated from the 15 radars shown in Fig. 6. Past studies have shown assimilating clear-air reflectivity to be effective in suppressing spurious cells (e.g., Tong and Xue 2005; Aksoy et al. 2009). Here, we consider the precipitation threshold to be $15 \mathrm{dBZ}$. Any observation less than $5 \mathrm{~dB} Z$ was set to $0 \mathrm{~dB} Z$, the clear-air value. Additionally, any first-guess reflectivity value less than $0 \mathrm{dBZ}$ was reset to $0 \mathrm{~dB} Z$ to ensure clear-air reflectivity could only have the effect of precipitation suppression. Note that there is a gap between 5 and $15 \mathrm{~dB} Z$ where the reflectivity observations were ignored (not assimilated) to prevent overlap in assimilation of precipitation and clearair observations near the edges of precipitation.

Covariance localization is used to ameliorate sampling error caused by having too few ensemble members relative to the model degrees of freedom (Houtekamer and Mitchell 1998, 2001). This study employs the commonly used Gaspari and Cohn (1999) function, a Gaussian-like function with an explicit cutoff radius. For the outer grid, a cutoff radius of $700 \mathrm{~km}$ was used horizontally, the same as by Johnson et al. (2015). On the inner grid, horizontal localization is varied dependent on observation type and network density, summarized in the last column of Table 3. For radar, the $20-\mathrm{km}$ cutoff is the same as used by Johnson et al. (2015) and similar to the $18-\mathrm{km}$ radius of Sobash and Stensrud (2013). For Oklahoma and West Texas Mesonets, we chose $80 \mathrm{~km}$ to allow some overlapping of localization functions based on their average station separation $(35 \mathrm{~km})$. A $40-\mathrm{km}$ localization radius was chosen for nonconventional surface observations (e.g., CWOP, ERNET) because they have much denser networks, particularly near major cities. In SS15, a $60-\mathrm{km}$ localization cutoff radius was used for all mesonet observations, so the values here are similar but more accurately reflect the different station density within the surface mesonet systems. Madaus and Hakim (2017) suggest an even smaller radius $(15 \mathrm{~km}$ in their case) may be necessary for capturing features leading to discrete CI, in the absence of strong mesoscale or synoptic-scale forcing; however, additional research in optimal localization (and inflation) requirements is still needed. While it is unclear if $40-\mathrm{km}$ localization is small enough to resolve convective-scale features leading to CI, it should still allow nonconventional observations to help resolve smaller meso- $\beta$-scale features associated with the dryline. Vertical localization cutoff for all observations was set to 0.55 in natural log pressure coordinates (approximately $4.5 \mathrm{~km}$ AGL over the DFW test bed).

Another error source that must be accounted for is intrinsic model error that is not represented within the ensemble. Covariance inflation methods can be used to correct for model error. Two methods of 
TABLE 2. WRF Model settings and physics parameterization schemes.

\begin{tabular}{ll}
\hline \multicolumn{1}{c}{ WRF setting } & \multicolumn{1}{c}{ Option chosen } \\
\hline Number of ensemble members & 43 \\
Initial conditions & SREF (21 members); GEFS (21 members); NAM (1 member) \\
& at 0300 UTC 3 Apr 2014 \\
Horizontal grid (outer domain) & $250 \times 180, \Delta x=12 \mathrm{~km}$ \\
Horizontal grid (inner domain) & $351 \times 351, \Delta x=2.4 \mathrm{~km}$ \\
Vertical grid & 50 levels, $p_{\text {top }}=50 \mathrm{hPa}$ \\
Cumulus scheme & Outer: Mixed \\
& Kain-Fritsch (Kain 2004) \\
& Betts-Miller-Janjić (Janjić 1994) \\
& Grell-Freitas ensemble (Grell and Freitas 2014) \\
& Grell 3D ensemble (Grell and Dévényi 2002) \\
& Inner: None \\
PBL scheme & MYNN level 2.5 (Nakanishi and Niino 2009) \\
Microphysics scheme & Thompson (Thompson et al. 2008) \\
LW radiation scheme & Rapid Radiative Transfer Model for global climate models \\
& (RRTMG; Iacono et al. 2008) \\
SW radiation scheme & New Goddard (Chou and Suarez 1999) \\
Land surface scheme & Noah (Tewari et al. 2004) \\
\hline
\end{tabular}

covariance inflation are applied as in Johnson et al. (2015): a height-dependent multiplicative inflation and relaxation to prior spread (RTPS; Whitaker and Hamill 2012). Further details on these inflation methods can be found in Johnson et al. (2015).

\section{c. Observation processing and quality control}

All conventional observations minus radar were obtained from the NAM Data Assimilation System
(NDAS) in PREPBUFR format. These observations were put through various automated quality control (QC) checks within the PREPBUFR processing (Keyser 2017). Nonconventional surface observations were obtained through MADIS and subjected to the same QC checks within the MADIS system, which uses several levels of checks including temporal and spatial consistency. Only MADIS observations that passed all levels of QC checks are assimilated in our

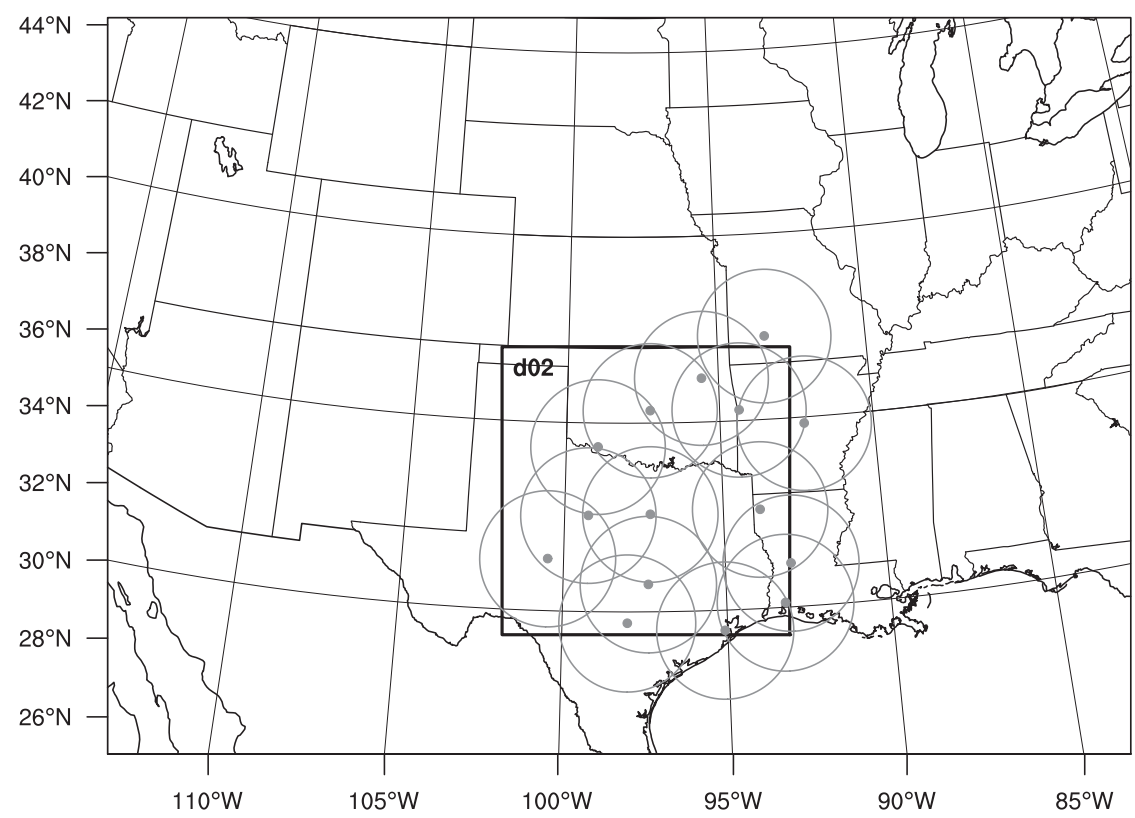

FIG. 6. WRF Model two-way nested grid setup. Outer domain has 12-km horizontal resolution, and inner grid $(\mathrm{d} 02)$ has $2.4-\mathrm{km}$ horizontal resolution (5:1 ratio). Dots indicate locations of WSR-88Ds used during inner-cycle DA, with circles representing 200-km ranges for each radar. 


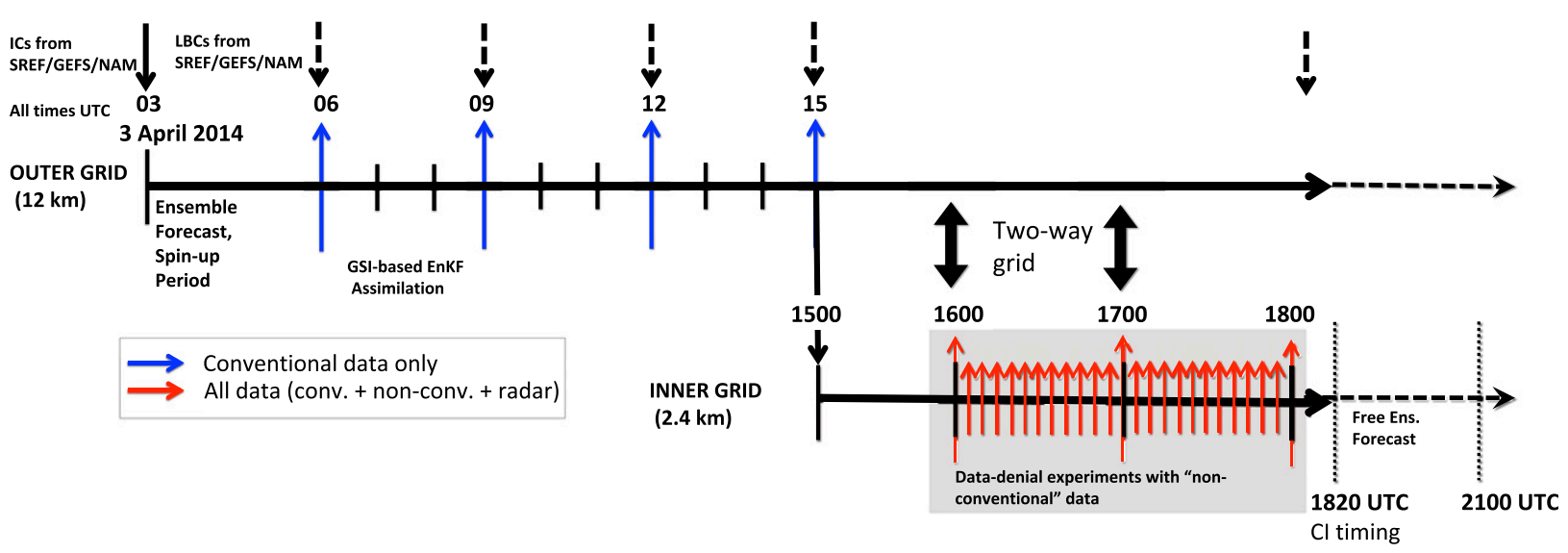

FIG. 7. Cycled DA experiment diagram. On the outer grid, after 3-h spinup, four 3-hourly DA cycles of conventional observations were performed, and inner grid was initialized at 1500 UTC. After 1-h spinup, 5-min DA cycling of all observations was performed for $2 \mathrm{~h}$ (1600-1800 UTC). Free ensemble forecast was initialized at 1800 UTC and run for $3 \mathrm{~h}$.

experiments. As in Johnson et al. (2015), radar observations were processed using the Warning Decision Support System-Integrated Information (WDSS-II; Lakshmanan et al. 2007) software. The GSI system itself performs additional QC gross error checks based on the ratio of the observation innovation to the observation error for a given observation.

An important consideration for this work is how to specify observation error values. Carlaw et al. (2015) showed that misspecification of error-in their case, specifying CWOP data to be as accurate as ASOS data-led to degradation in verification scores. Values for initial observation error are shown in Table 3. They were based on similar values used by Carlaw et al. (2015) but further tuned for the GSI system. These values are initially smaller than what was used by Carlaw et al. (2015) because the GSI automatically adjusts (inflates) observation errors based on mismatches between observation pressure and the first-guess pressure, including a higher penalty if the observation is below the model terrain height. Since nonconventional data have enhanced siting issues more often than conventional data, they more frequently have large differences in observed pressure compared to the model first-guess pressure. The automatic observation error inflation within GSI is proportional to these pressure differences, and as a result, the error inflation for nonconventional observations is generally higher.

\section{d. Data denial experiment setup}

Data denial experiments were done within the 5-min DA cycling from 1600 to 1800 UTC on the inner grid (Fig. 7). The locations of all observations assimilated within this period are shown in Fig. 8. Surface data are abundant within the DFW metroplex. Near the dryline, the observations are sparser, though there is some coverage of nonconventional observations. The temporal interval of surface observations varies by dataset. ASOS and AWOS were available every $20 \mathrm{~min}$, and ERNET and conventional mesonets every $5 \mathrm{~min}$. CWOP data were more intermittent; most locations had observations available every $5 \mathrm{~min}$, others every $10-15 \mathrm{~min}$, and some remote locations reported less frequently. The miscellaneous mesonet data had a variety of reporting intervals, from $15 \mathrm{~min}$ to just hourly.

TABLE 3. Initial observation error table values used for surface and radar datasets. Last column indicates localization scale used for each data source.

\begin{tabular}{lcccccrr}
\hline \hline \multicolumn{1}{c}{ Data source } & $P_{s}(\mathrm{hPa})$ & $T\left({ }^{\circ} \mathrm{C}\right)$ & $\mathrm{RH}(\%)$ & $u v\left(\mathrm{~m} \mathrm{~s}^{-1}\right)$ & $Z(\mathrm{dBZ})$ & $V_{R}\left(\mathrm{~m} \mathrm{~s}^{-1}\right)$ & Localization scale $(\mathrm{km})^{-1}$ \\
\hline NEXRAD & - & - & - & - & 5.0 & 2.0 & 20 \\
ASOS/AWOS & 0.5426 & 0.8 & 2.705 & 1.5 & - & - & -200 \\
OK/WTX Mesonet & 0.75 & 1.0 & 3.5 & 1.5 & - & - & 40 \\
ERNET & 1.125 & 1.5 & 5.0 & 2.0 & - & - & 40 \\
CWOP & 1.5 & 2.0 & 7.0 & 2.5 & - & - & 40 \\
MoPED & 1.125 & 1.5 & 5.0 & - & - & - & 40 \\
Miscellaneous mesonet & 1.125 & 1.5 & 5.0 & 2.0 & - & - \\
\hline
\end{tabular}




\begin{tabular}{|ll|}
\hline & Sounding \\
+ & Wind Profiler \\
- & Aircraft \\
- & GPOS/AWOS IPW \\
- & OK/WTX Mesonet \\
- & ERNET \\
- & MoPED \\
\hline & Misc. Mesonet \\
\hline
\end{tabular}

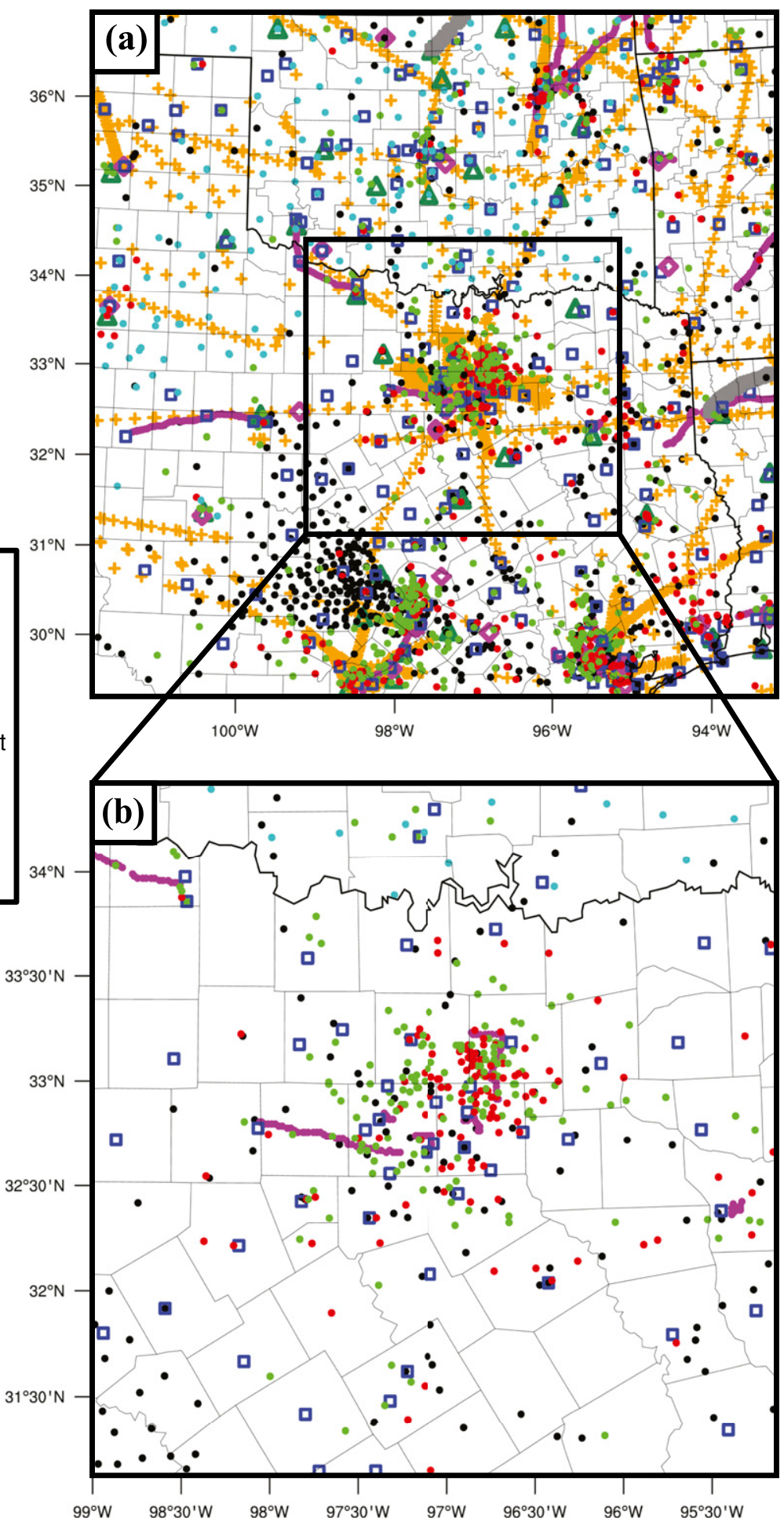

FIG. 8. (a) Locations of all observations assimilated on inner domain between 1600 and 1800 UTC. (b) All surface observations available from 1600 to1800 UTC, zoomed into the DFW region. 
TABLE 4. Summary of surface data denial experiments.

\begin{tabular}{|c|c|c|c|c|c|c|}
\hline Experiment name & ASOS/AWOS & OK/WTX Mesonet & ERNET & CWOP & MoPED & Miscellaneous mesonet \\
\hline CNTL & Yes & Yes & Yes & Yes & Yes & Yes \\
\hline NOSFC & No & No & No & No & No & No \\
\hline NONEWSFC & Yes & Yes & No & No & No & No \\
\hline denyASOS & No & Yes & Yes & Yes & Yes & Yes \\
\hline denyERNET & Yes & Yes & No & Yes & Yes & Yes \\
\hline denyCWOP & Yes & Yes & Yes & No & Yes & Yes \\
\hline denyCW & Yes & Yes & No & No & Yes & Yes \\
\hline denyMISC & Yes & Yes & Yes & Yes & Yes & No \\
\hline denyCWwnd & Yes & Yes & Yes (thermo) & Yes (thermo) & Yes & Yes \\
\hline
\end{tabular}

All data denial experiments are listed in Table 4. The control experiment (CNTL) uses all available data. Experiment NOSFC is a baseline experiment to evaluate effects of not using any surface data on the innerdomain DA for the CI forecast (outer-domain DA is left unchanged), while NONEWSFC denies just nonconventional surface observations in DFW. Other denial experiments are performed to evaluate the relative impacts of each observational dataset. The experiment denying ASOS data (denyASOS) is presented as another point of comparison with the other nonconventional denials. Finally, given that Carlaw et al. (2015) showed the majority of positive benefit coming from thermodynamic variables, an experiment denying just wind information from CWOP and ERNET (denyCWwnd) is also considered to separate out the relative impacts from thermodynamic and wind observations.

\section{e. Methods for assessing forecast quality}

There are a few methods of evaluating the experiment forecast output for CI. First, we use a subjective evaluation of ensemble probability of composite reflectivity (CREF) exceeding $35 \mathrm{dBZ}$ for various time intervals. This threshold is common for identification of active ongoing convection (e.g., Roberts and Rutledge 2003). Since this is an extreme hail event for the DFW test bed, another method of evaluation is the examination of maximum hail size produced within the model throughout the 3-h free forecast. Given larger uncertainty in hail prediction, we employ a neighborhood ensemble probability (NEP) method: for each ensemble member, the fraction of points exceeding the threshold value within a neighborhood radius is calculated at all model grid points then averaged across all ensemble members (Schwartz et al. 2010). For hail, two thresholds are considered: 10 and $25 \mathrm{~mm}$. The former is used as the lower limit of hail, slightly larger than pea size; the latter is approximately the threshold for severe hail used by the U.S. National Weather Service. The NEP output is compared with SPC and mPING report locations gathered between 1800 and 2100 UTC. Differences in near-surface fields relative to the CNTL help to diagnose the differences seen in the CI performance among denial experiments, in addition to comparisons of root-mean-square differences (RMSDs) and bias statistics.

\section{Results}

\section{a. Evaluation of CNTL experiment}

The evolution of the severe weather event on the inner domain is shown in Fig. 9. In addition to the two supercells in the DFW region, another area of CI is observed in northeast Oklahoma along the advancing cold front between 1800 and 1900 UTC (Figs. 9a,b). This line of storms stretches southwest into central Oklahoma. Another area of CI occurs in southwest Texas between 1900 and 1930 UTC. Throughout the 3-h free ensemble forecast, CNTL captures the Oklahoma line of storms with very high confidence, as probabilities are shown exceeding $90 \%$ for a large portion of the line and as high as $100 \%$ for an early part of the line (Fig. 9c). There is less confidence in the southwestern extent of the line, but still over half the ensemble members indicate convection extending that far south. The storms of interest near Dallas are also captured very well in this 3-h view, with probabilities exceeding $90 \%$. Convection also initiates to the southwest in the ensemble and appears overaggressive, compared to reality. There are additional points of observed CI in this area after 2100 UTC (not shown), so we consider this forecast reflectivity to be early CI rather than completely spurious.

Within the DFW region, the ensemble shows CI activity very quickly after the 1800 UTC final analysis time, as shown in the top row of Fig. 10. Already 10-20 min into the forecast, probabilities of CREF $\geq$ $35 \mathrm{dBZ}$ as high as $90 \%$ are seen in southwest Wise County, centered less than $10 \mathrm{~km}$ from the actual CI 


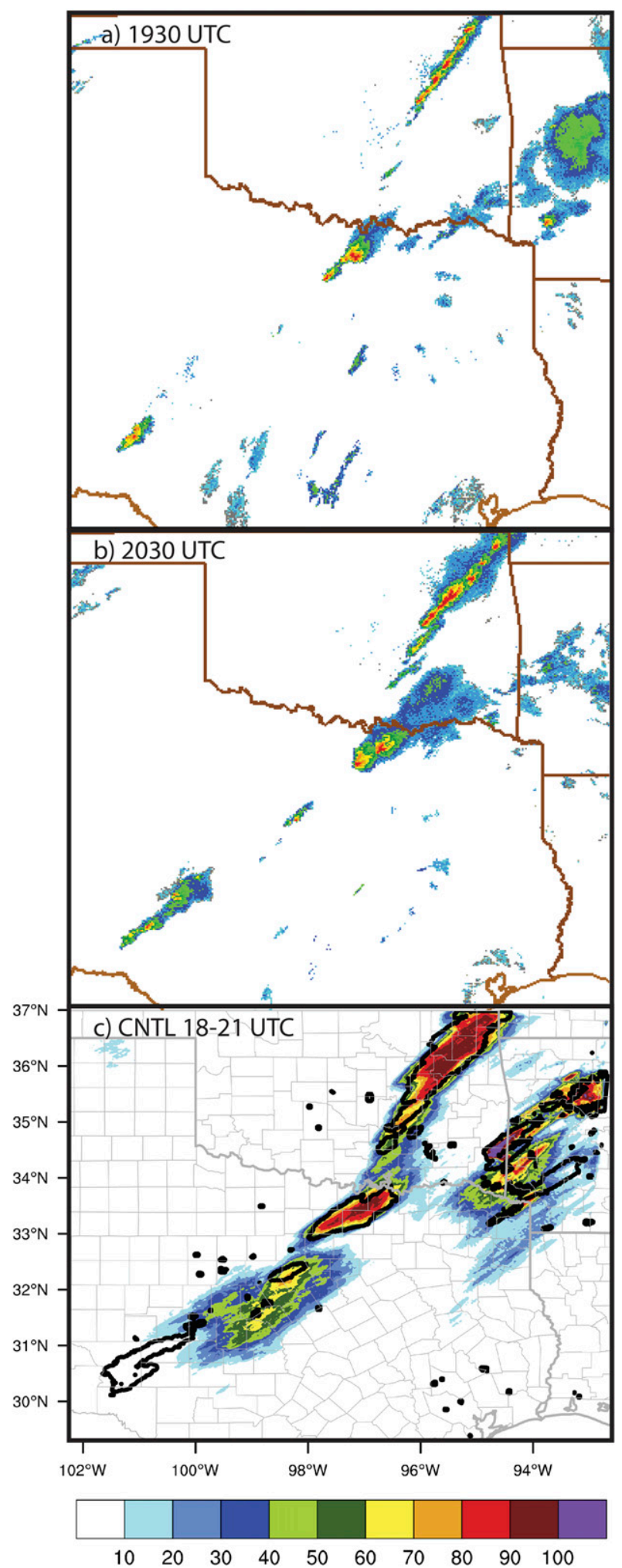

FIG. 9. (a),(b) Observed composite reflectivity mosaic valid 1930 and 2030 UTC 3 Apr 2014, respectively. (c) Ensemble probability of maximum 3-h (1800-2100 UTC) composite reflectivity $\geq 35 \mathrm{dBZ}$ (\%), with observed 35-dBZ maximum 3-h composite reflectivity (black contours). location (Fig. 10a). Probabilities remain above $70 \%$ by 1850 UTC with a general collocation with the actual storm extent (Fig. 10c). There are, however, spurious CI locations nearby, with a couple areas to the northeast showing probabilities greater than $50 \%$ in the ensemble. By 1850 UTC, the swath of probabilities exceeding $30 \%$ extends from southwest Wise County up to the Oklahoma-Texas border (Fig. 10c).

The output of maximum hail size NEP is shown in Fig. 11. The ensemble has high confidence in hail exceeding $10 \mathrm{~mm}$ and covers nearly all hail reports with above $50 \%$ probability (Fig. 11a). There is a slight northern bias to the hail swath, however, as probabilities above $70 \%$ extend as far north as Oklahoma. With the higher severe threshold of $25 \mathrm{~mm}$, probabilities are significantly reduced. There are two distinct centers of probability exceeding $50 \%$. The first is in southwest Wise County, just to the southwest of the hail reportsan indication that the model grew the storms too quickly and aggressively, compared to reality. The second peak is stronger and covers a larger area, with the center approximately $20-30 \mathrm{~km}$ northeast of the maximum hail size reports located in Denton, Texas. Despite the small location errors, the CNTL ensemble was able to predict with high confidence severe hail in the north DFW region. In summary, despite some premature CI in west Texas, the CNTL experiment successfully forecast the storms near the area of focus for this study - the DFW test bed-very similar to what happened in reality in terms of CI location, timing, and storm mode. The credibility of denial experiments within OSE studies relies on having a CNTL experiment that is accurate.

\section{b. Evaluation of denial experiments}

In addition to CNTL, experiments denyASOS and NOSFC are shown in Fig. 10. As seen in Figs. 10d-f, there is a substantial impact in the CI forecast from denying ASOS and AWOS observations, with the main area of CI shifted about $65 \mathrm{~km}$ to the northeast, close to the Oklahoma border. Additionally, this CI was delayed by about $15 \mathrm{~min}$, compared to the CNTL. A much larger negative impact is seen when assimilating no surface observations (Figs. $10 \mathrm{~g}-\mathrm{i}$ ), where minimal $\mathrm{CI}$ occurs in the ensemble within the first hour. This result of experiment NOSFC is an important baseline to show the impact that any surface observations have on the CI forecast-in this case, CI is highly sensitive to surface observations. Comparing NOSFC to denyASOS, we can infer that nonconventional observations have added significant value in capturing CI, even though there are larger timing and location errors in denyASOS than CNTL. 
1810-1820 UTC
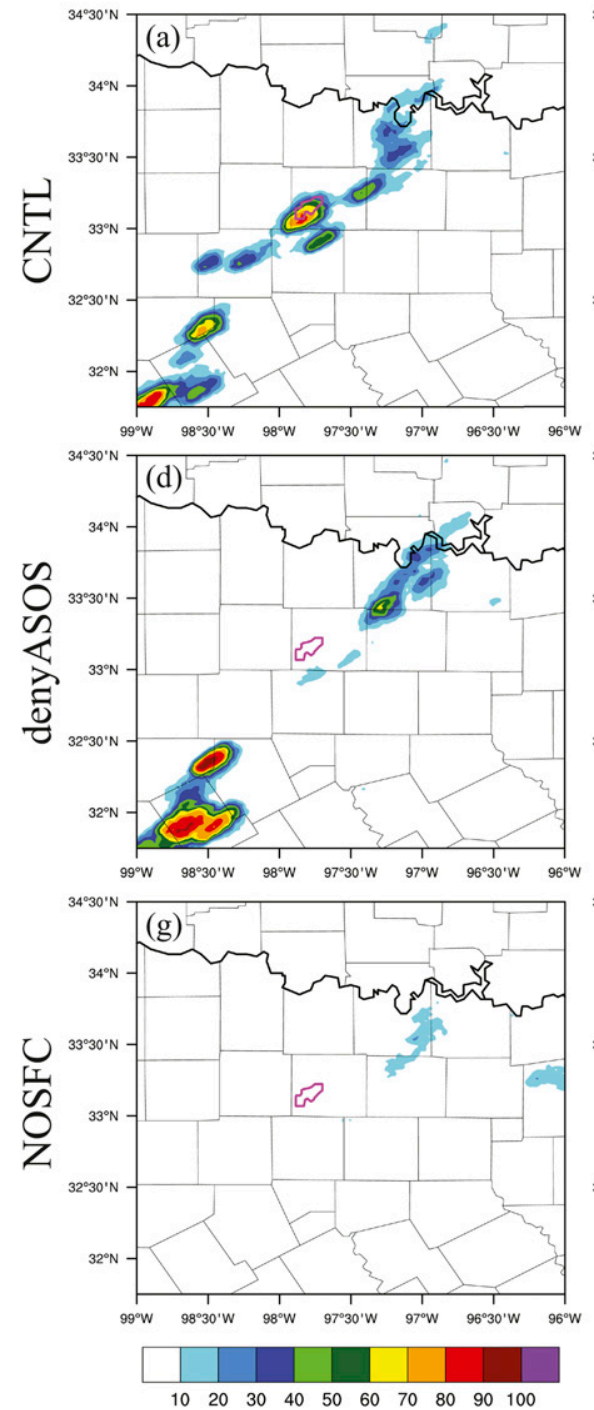

1825-1835 UTC
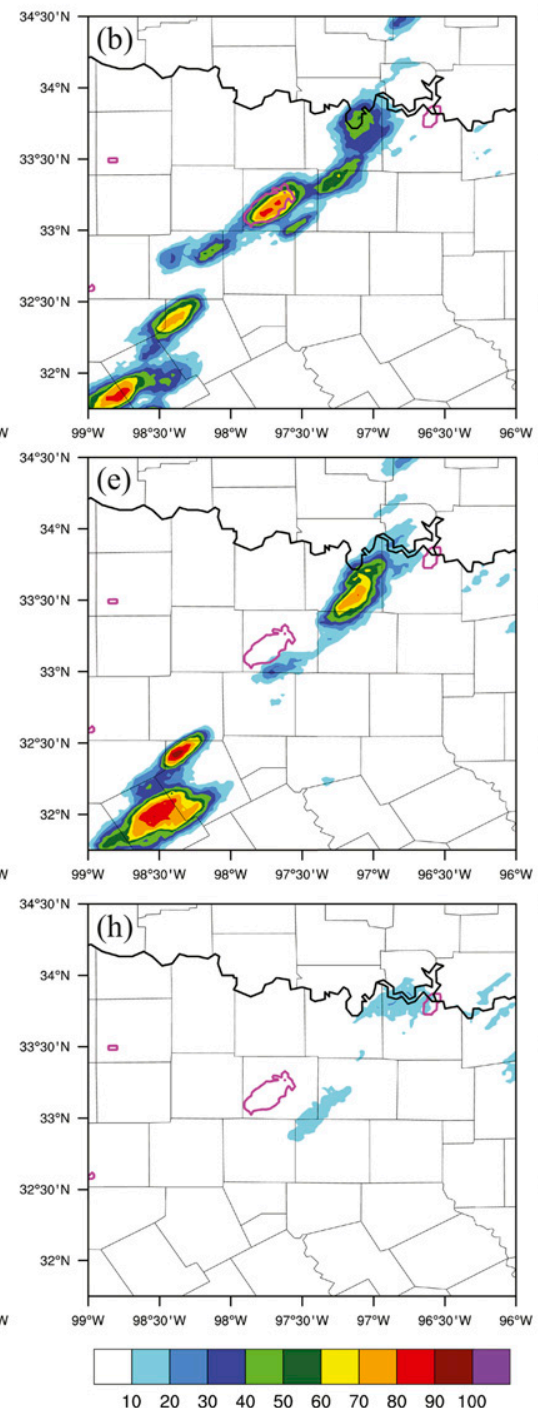

1840-1850 UTC
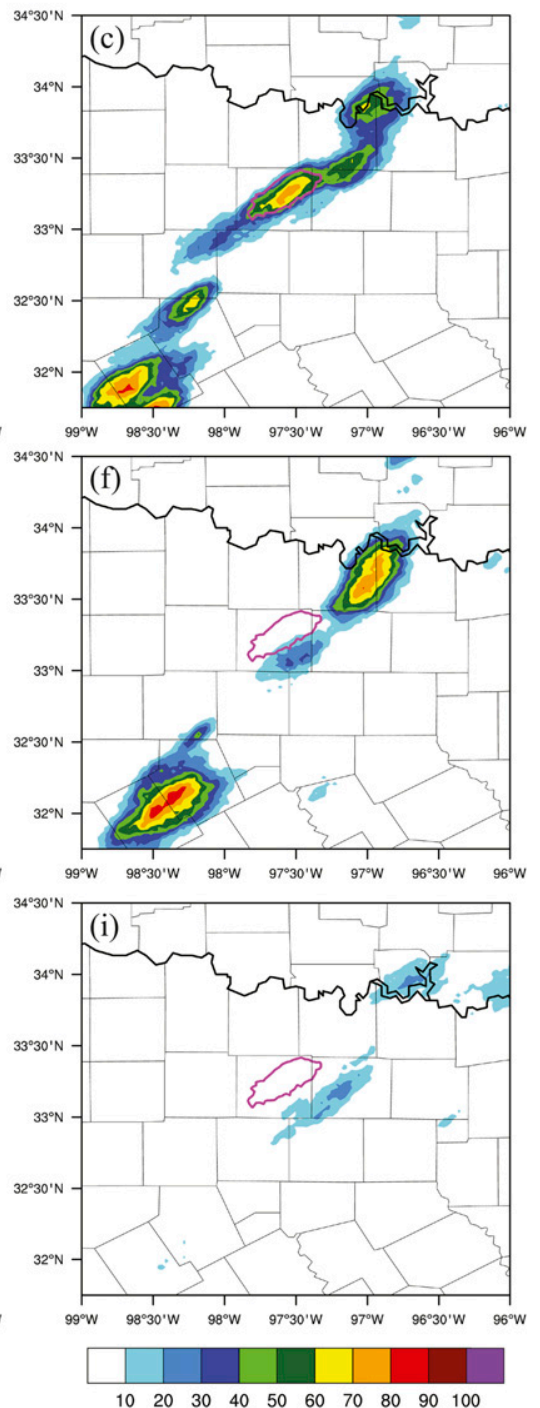

FIG. 10. Ensemble probability of 10 -min maximum composite reflectivity greater than $35 \mathrm{~dB} Z$ for experiments (a)-(c) CNTL, (d)-(f) denyASOS, and (g)-(i) NOSFC. Magenta contour indicates observed maximum 10-min composite reflectivity for each time period indicated.

Ensemble probabilities of $\mathrm{CREF} \geq 35 \mathrm{~dB} Z$ for experiments denying nonconventional observations are shown in Fig. 12. The differences are generally smaller than the differences shown in Fig. 10; however, there are still some notable effects. When denying all nonconventional data (NONEWSFC), the CI in southwest Wise County is reduced in probability to below $40 \%$, though two additional CI points just south and southwest show probabilities in the $40 \%-50 \%$ range. Additionally, a spurious point of CI occurs by the Oklahoma border, with probabilities over $80 \%$ (Fig. 12a). This storm dissipates rapidly within the ensemble. For experiment denyERNET, there are many more spurious $\mathrm{CI}$ locations within the ensemble; additionally, the Wise County CI shows probabilities no higher than $60 \%$, which is a small reduction, compared to CNTL (Figs. 12d-f). On the other hand, denyCWOP shows a marked reduction in the number of spurious CI points within the DFW region, though the CI in Wise County is reduced $10 \%$ more in probability, as compared to denyERNET. Taken together, there are mixed signals in positive and negative impacts. We can infer that CWOP data are important in establishing the CI in Wise County; however, CWOP also contribute to the amount of spurious $\mathrm{CI}$ in the ensemble. While ERNET data have a bit less impact on the CI itself, they do help counteract the spurious activity. 

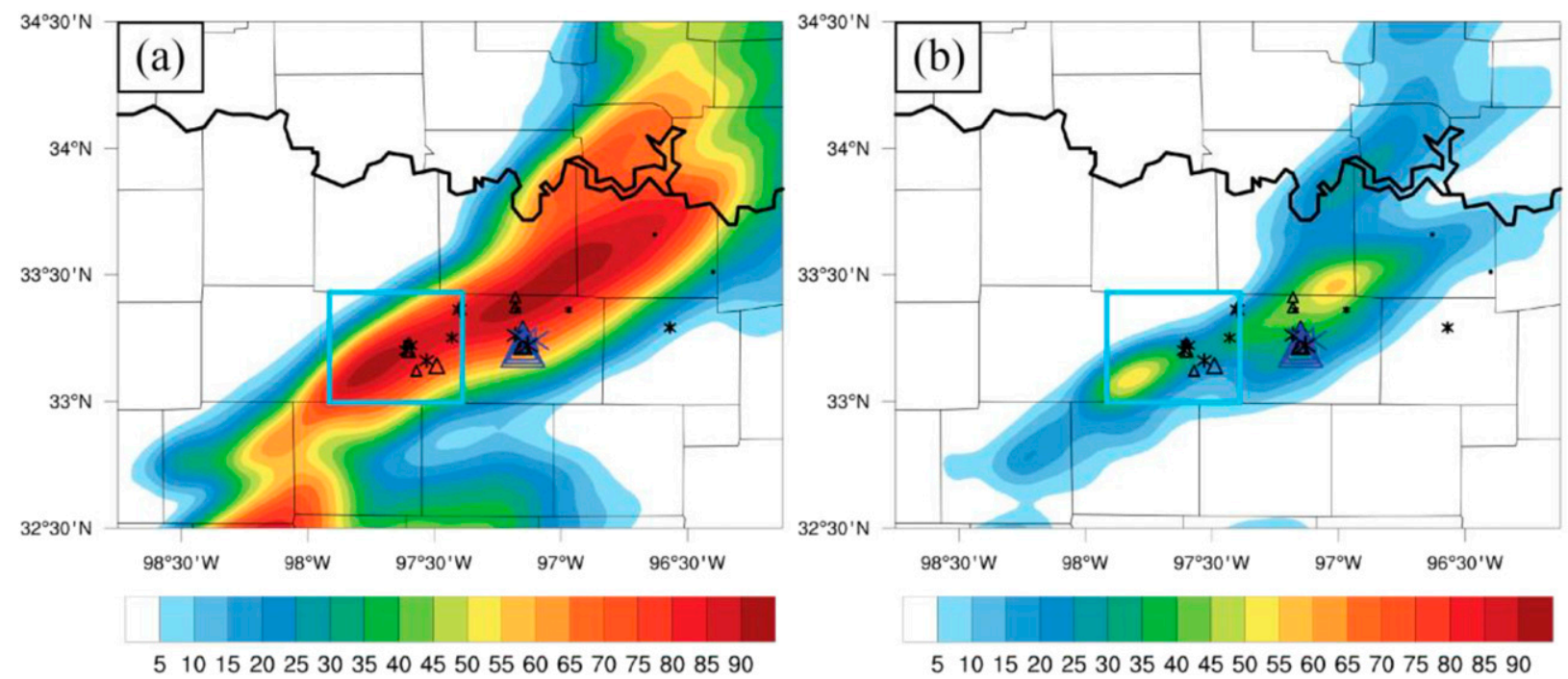

FIG. 11. Neighborhood ensemble probability of maximum hail size in the entire column exceeding (a) 10 and (b) $25 \mathrm{~mm}$ for the entire 3-h forecast period (1800-2100 UTC) plotted for the CNTL experiment using a neighborhood radius of 9.6 km. Triangles indicate SPC hail reports, and asterisks indicate mPING hail reports, sized according to size of the hail reported. Wise County, TX, is highlighted by the blue box.

When looking at NEP of maximum hail $\geq 10 \mathrm{~mm}$ (Fig. 13), denyASOS is again displaced to the northeast, close to the Oklahoma border. Denying ERNET has a minor effect on the $10-\mathrm{mm}$ hail forecast, but denying CWOP data constrains the hail swath to more closely match the report locations, eliminating much of the northerly extent of hail (Fig. 13c). Experiment NONEWSFC shows reduced probabilities-less than $70 \%$ - and smaller hail swaths, though the location is still closer to the hail reports. A similar pattern can be seen with the NEP of 25-mm hail (Fig. 14). There is a small northeast displacement of the maximum hail probability in denyERNET, and probabilities are reduced slightly (around 10\%), compared to CNTL (Fig. 14b). There is less displacement in denyCWOP, but the probabilities are again reduced by around $10 \%$, compared to CNTL (Fig. 14c). In NONEWSFC, less than $1 / 4$ of ensemble members show severe hail, which is as much as $40 \%$ lower than the CNTL (Fig. 14d); less than $15 \%$ of ensemble members have severe hail in NOSFC (Fig. 14f).

\section{c. Evaluation of surface fields}

Since CI is especially sensitive to boundary layer moisture for dryline cases, it is important to look at the surface moisture field to gain insight into some of the differences shown in the ensemble probability fields. Dewpoint temperature for the final mean analysis is shown for CNTL and NOSFC in Figs. 15a and 15b, respectively. The actual dryline placement error is not very large in NOSFC, compared to CNTL. However, there are several other notable differences in the dryline that led to much smaller location and timing errors of CI in CNTL. First, the dryline in CNTL has stronger gradients and shows higher values of moisture in general. The dryline in NOSFC is overmixed and has coarser gradients; as a result, a large part of Wise County (blue rectangle) and counties to its southwest are much drier than CNTL, which has an accurate depiction of moisture, compared to nearby observations. Additionally, there are important kinks in the dryline in CNTL that are not as apparent in NOSFC. Several studies have linked CI to dryline bulges and kinks such as that seen in CNTL (e.g., Hane et al. 1997, 2002; SS15; Hill et al. 2016). Near the CI location, the local dryline is approximately east-west in orientation in CNTL, whereas in NOSFC, no such small-scale variation exists. Because of the east-west local variation, an area of enhanced convergence exists owing to the largely southerly flow in the moist regime being locally perpendicular to the dryline. Additionally, there appears to be a small pocket of enhanced moisture in that location.

Of course, it can be challenging to look at a moisture plot and simply point to an exact location of CI. Not all dryline kinks result in convection. One avenue to address this is to look at plots of moisture flux convergence (MFC) to identify favorable areas of CI (Banacos and Schultz 2005). While the utility of a snapshot of MFC is questionable in a forecasting sense, it can be used as an important visual tool for CI case studies. One example is Xue and Martin (2006a,b), who, with the aid of MFC plots, 
1810-1820 UTC
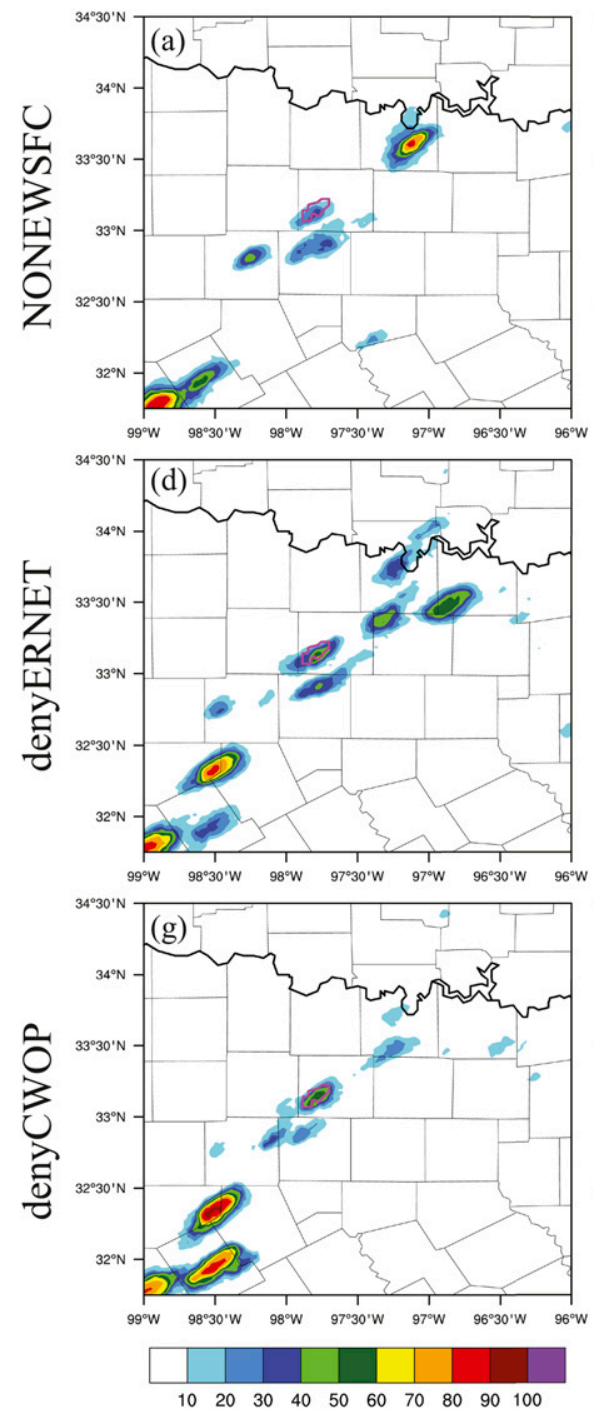

1825-1835 UTC
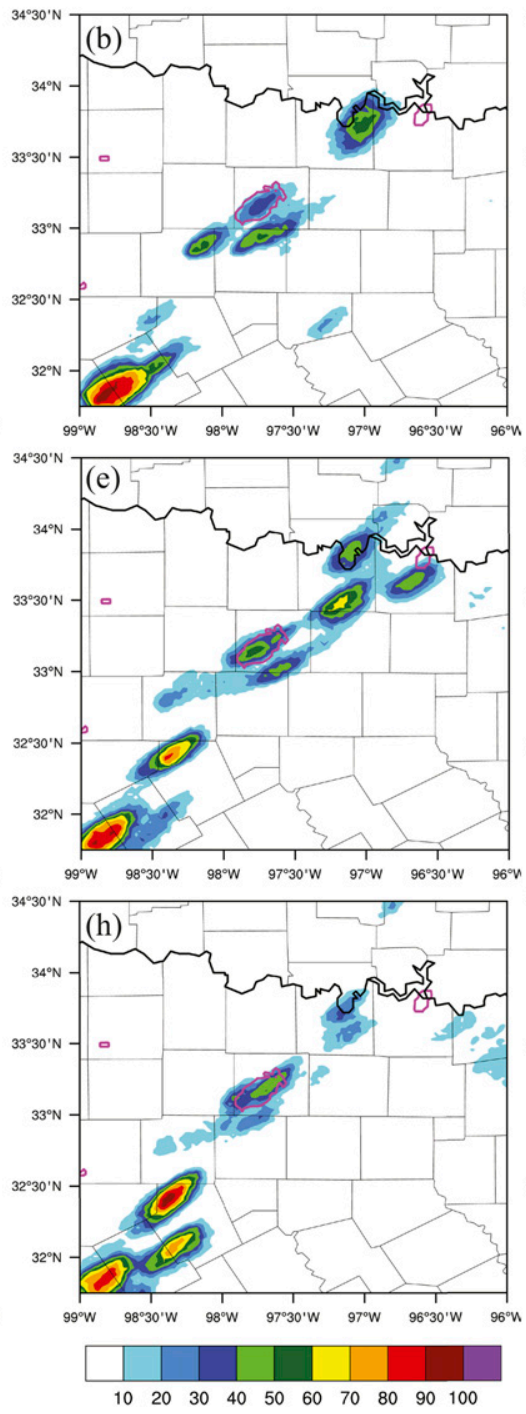

1840-1850 UTC
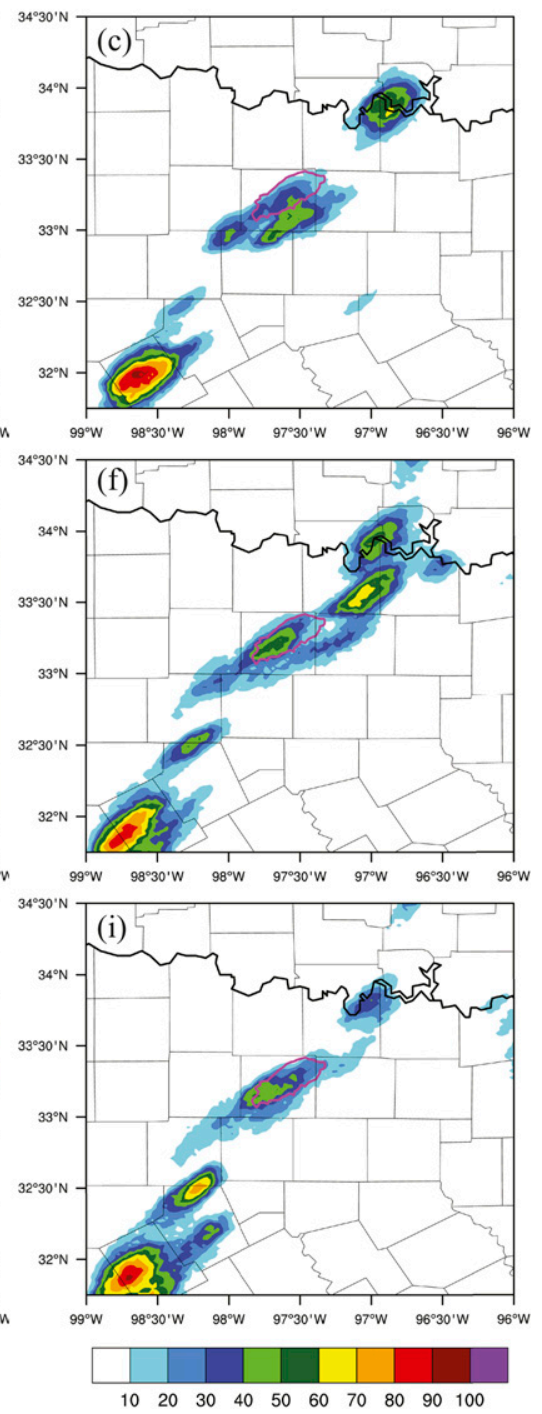

FIG. 12. As in Fig. 10, but for experiments (a)-(c) NONEWSFC, (d)-(f) denyERNET, and (g)-(i) denyCWOP.

developed a conceptual model for dryline CI that posits locations of enhanced convergence that occur at intersections between boundary layer convective rolls and the primary dryline convergence band. It is possible the east-west kink in Fig. 15a is a reflection of such a process, though the horizontal resolution of this forecast is too coarse to fully resolve convective rolls in the PBL.

A drawback of MFC is that it only reflects a single level, while $\mathrm{CI}$ is a $3 \mathrm{D}$ process that requires enough convergence to lift parcels to the level of free convection. Plots of MFC along the dryline often show many areas of enhanced convergence; thus, it may not discriminate very well between areas where CI occurs and where it does not. For this reason, we have instead plotted vertically integrated MFC (VIMFC) over the lowest $2 \mathrm{~km}$ of the atmosphere to reflect the amount of forced lifting in the PBL. VIMFC was explored as a discriminator on synoptic scales by van Zomeren and van Delden (2007); however, to the best of our knowledge, it has not been used for convective scales. VIMFC is analogous to precipitable water in that it reflects the depth of water vapor between two vertical levels if it condensed at the bottom of a column with a $1-\mathrm{m}^{2}$ base; in the case of VIMFC, it reflects the liquid equivalent depth of water entering the column per second. As seen in Fig. 15c, CNTL has a strong center of VIMFC associated with the east-west local kink near Wise County, indicating that this location is strongly favored for $\mathrm{CI}$; this helps explain why timing 

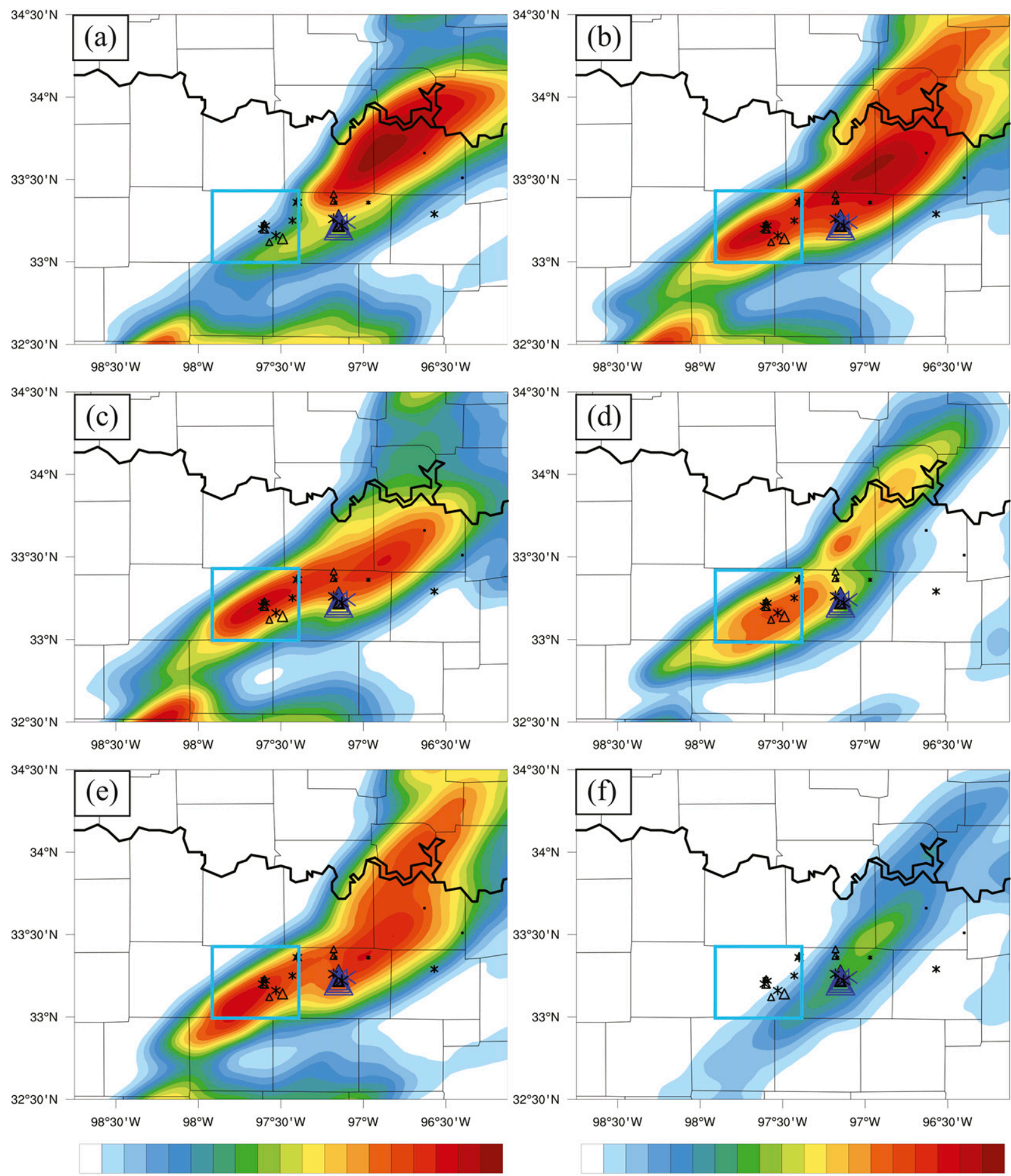

51015202530354045505560657075808590

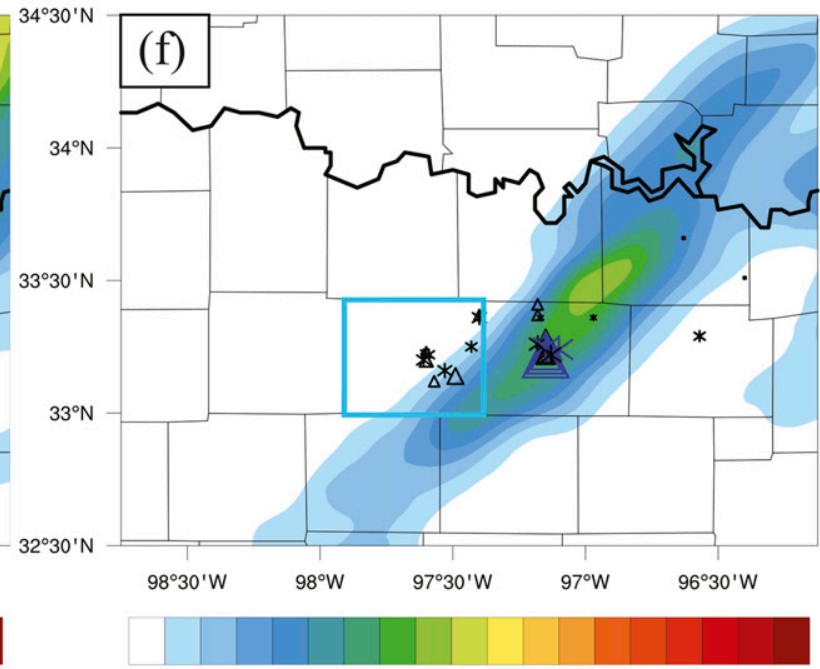

51015202530354045505560657075808590

FIG. 13. As in Fig. 11a, but for denial experiments (a) denyASOS, (b) denyERNET, (c) denyCWOP, (d) NONEWSFC, (e) denyMISC, and (f) NOSFC. 

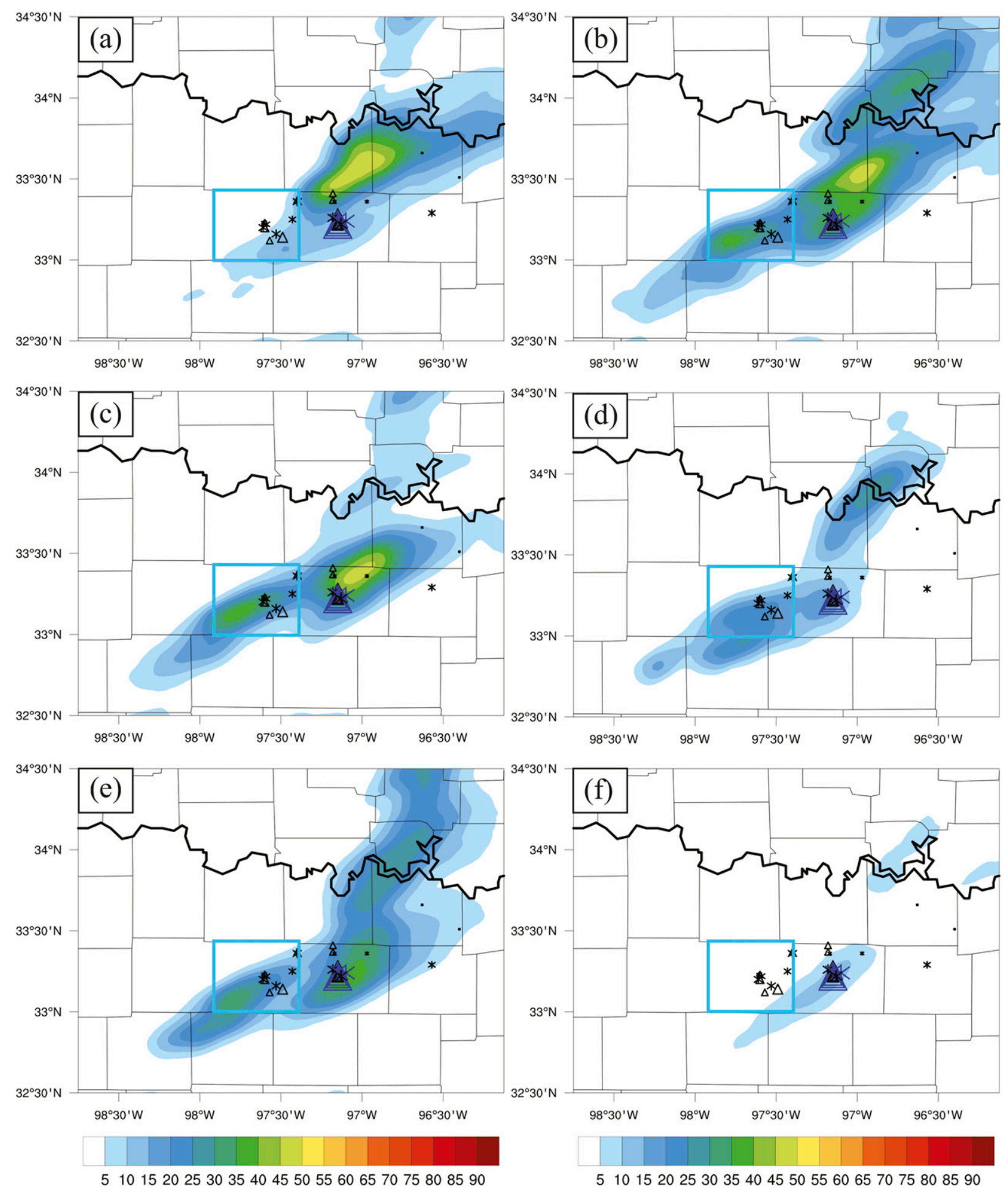

FIG. 14. As in Fig. 11b, but for denial experiments (a) denyASOS, (b) denyERNET, (c) denyCWOP, (d) NONEWSFC, (e) denyMISC, and (f) NOSFC 

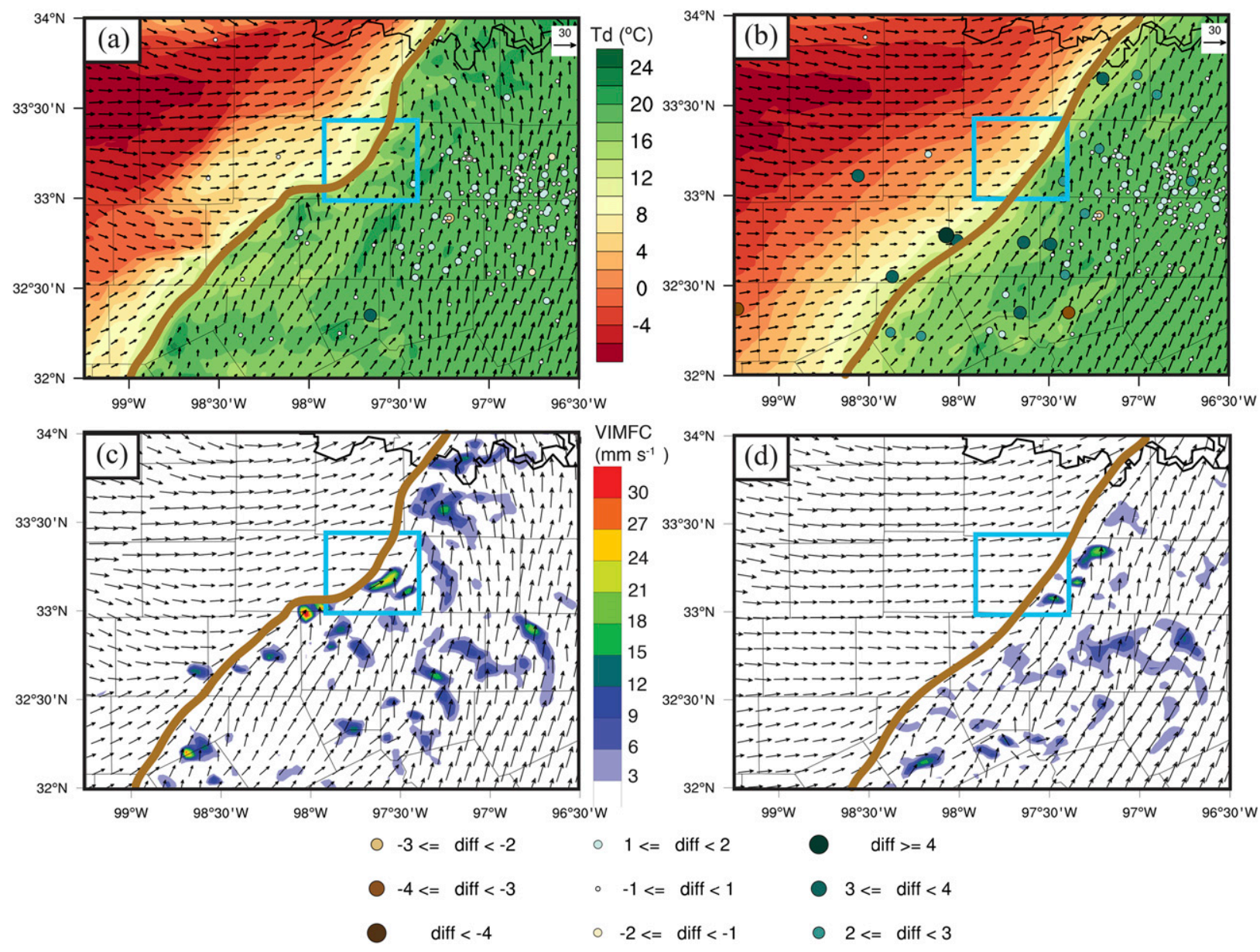

FIG. 15. (a),(b) Final analysis mean 10-m dewpoint temperature (color fill) and wind (vectors), valid 1800 UTC 3 Apr 2014, for experiments CNTL and NOSFC, respectively. Color-filled dots indicate observed-minus-analysis moisture values (specific humidity; $\mathrm{g} \mathrm{kg}^{-1}$ ) from all surface observations at 1800 UTC. (c),(d) Vertically integrated moisture flux convergence $\left(\mathrm{mm} \mathrm{H}_{2} \mathrm{O} \mathrm{s}{ }^{-1}\right.$ ) computed for the lowest $2 \mathrm{~km}$ above ground level, with wind (vectors) at $2 \mathrm{~km}$ above ground, valid 1800 UTC 3 Apr 2014 for experiments CNTL and NOSFC, respectively. Thick brown line indicates approximate dryline location, and blue box indicates location of Wise County, TX.

and location errors were very small in CNTL for this cell. On the other hand, VIMFC shows little to no favorable CI areas in NOSFC (Fig. 15d).

Difference fields of dewpoint are shown in Fig. 16 to help show the origins of the enhanced VIMFC. Overlaid on these difference plots are the denied observations minus the analysis, which can be thought of as the observation innovation that the denied observations would have had if they were assimilated in the denial experiment. The goal of this is to clearly tie the differences between the CNTL and denial experimentswhich include nonlinear effects of model integration-to the actual observations had they been assimilated. From Fig. 16a, there are a few ERNET observations upstream of the CI location in relatively data-sparse locations that help feed moisture to the CI location. The CWOP data-which had a larger impact on the
CI probability-have fortuitous data coverage near the CI location to help capture that east-west kink in the dryline, as locally there are dry and moist observations directly north and south of each other right next to that CI location (Fig. 16b). ASOS data, which had the largest impact of the surface datasets, can be seen to have more broad-scale impacts in Fig. 16c, which helps to constrain the gradient and location of the dryline from the overmixing tendency found within NOSFC.

Finally, the miscellaneous mesonet data had a surprising impact on the moisture field, as observations well southwest of the CI location were found to feed directly to that location in a "river of moisture" after $2 \mathrm{~h}$ of model integration. Denying these data did have a slightly larger negative impact in terms of severe hail (Fig. 14e) than either denyCWOP or denyERNET. 

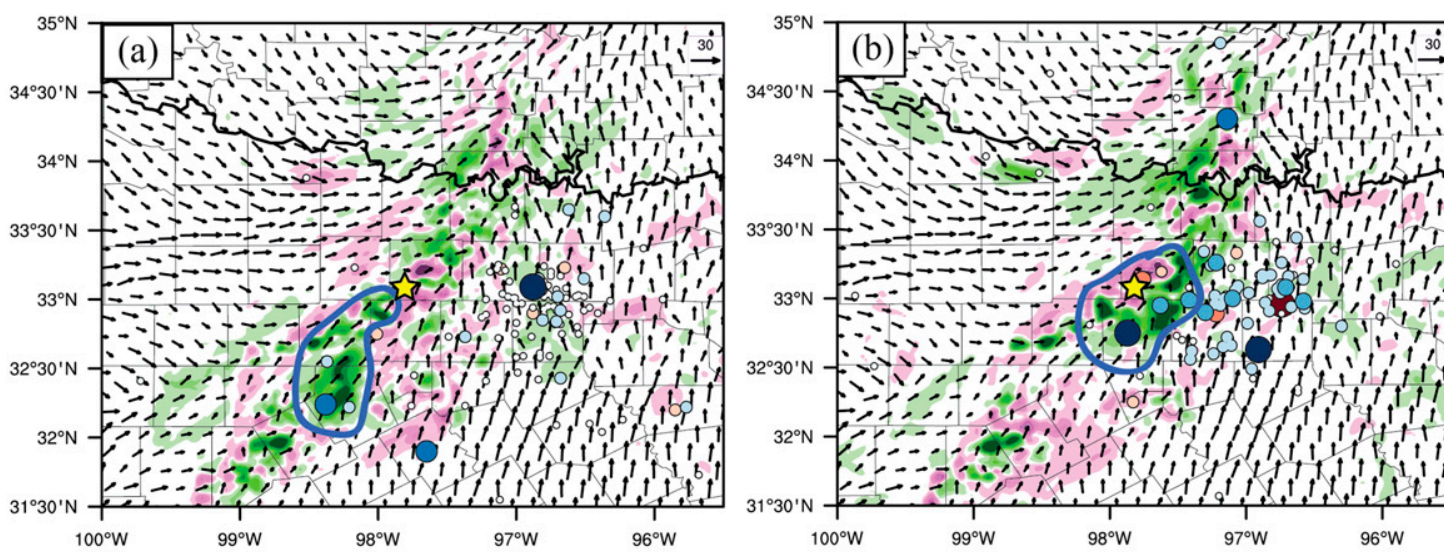

$\Delta \operatorname{Td}\left({ }^{\circ} \mathrm{C}\right)$
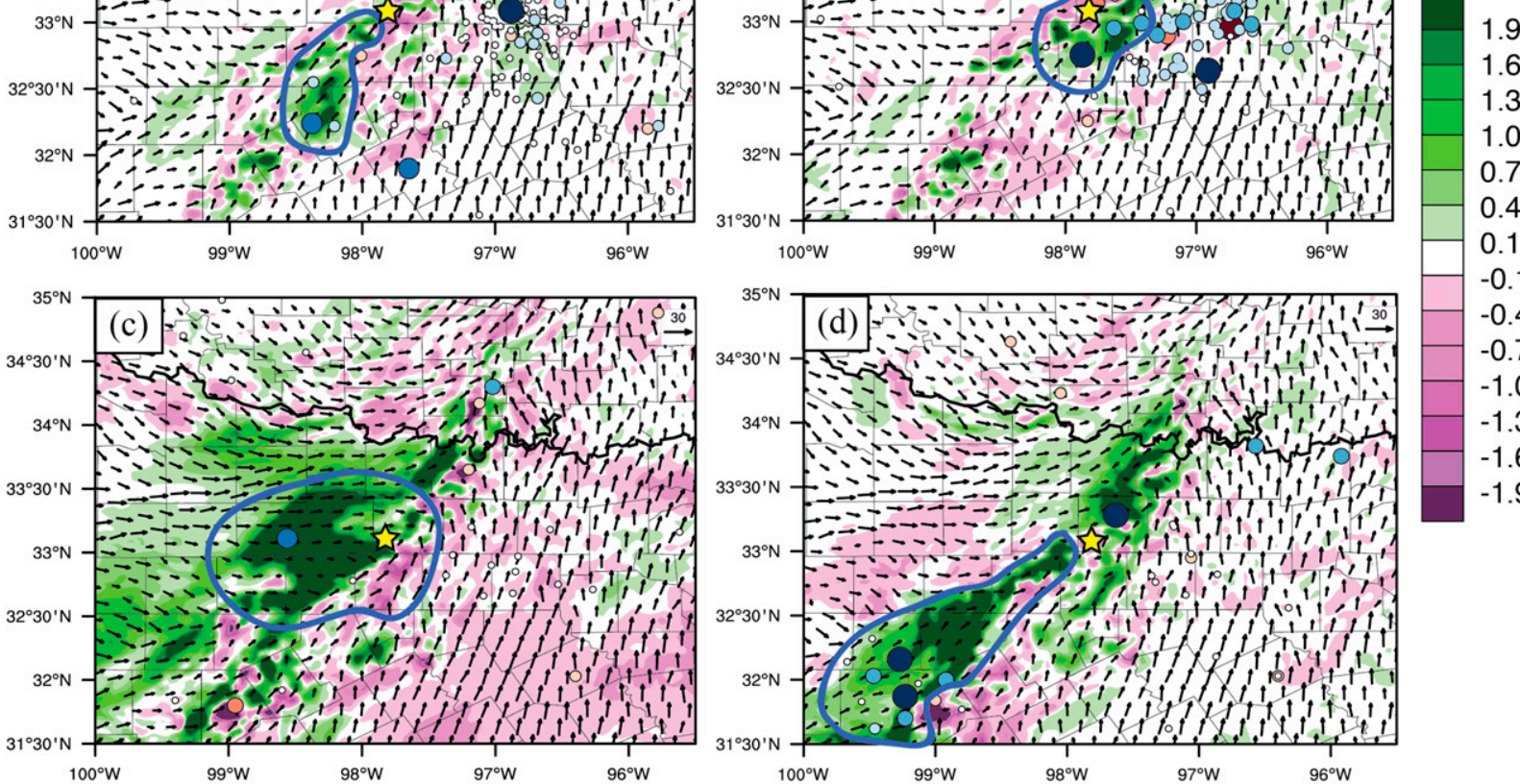

$$
35
$$

\section{(n)}$$
100^{\circ} \mathrm{W}
$$

$$
99^{\circ} \mathrm{W}
$$$$
\text { - }-3<=\text { diff }<-2
$$$$
-4<=\operatorname{diff}<-3
$$$$
\text { - } 1<=\operatorname{diff}<2
$$$$
\text { - }-1<=\text { diff }<1
$$$$
\text { diff }<-4
$$$$
\text { - }-2<=\operatorname{diff}<-1
$$

$$
\begin{gathered}
\text { diff }>=4 \\
3<=\text { diff }<4 \\
2<=\operatorname{diff}<3
\end{gathered}
$$

FIG. 16. Difference fields for ensemble mean 2-m dewpoint temperature (color fill) and 10-m wind (vectors) for final analysis time 1800 UTC 3 Apr 2014: (a) denyERNET minus CNTL, (b) denyCWOP minus CNTL, (c) denyASOS minus CNTL, and (d) denyMISC minus CNTL. Color-filled dots indicate respective denied observations from each denial experiment for each plot, with colors and sizes indicating the $O-A$ values (specific humidity; $\mathrm{g} \mathrm{kg}^{-1}$ ) for each denial dataset (i.e., what the observation innovations would have been if denied observations were assimilated). Yellow star indicates approximate CI location, and blue outlines highlight relevant observations influencing the $\mathrm{CI}$ forecast.

These observations to the southwest were from a hydrometeorological observation network, located often next to small lakes and streams.

In summary, Fig. 16 indicates that there is a cumulative effect of all these different observations. Each network is adding moisture in a different way. This helps explain why the location and timing of CI were not greatly affected by the nonconventional denials, but the ensemble probabilities of $\mathrm{CI}$ and hail were reduced.

Error statistics for all experiments are shown in Fig. 17, computed against all surface observations available. The RMSD and biases shown before the start of the free forecast (negative times) were calculated using first-guess and analysis ensemble means during DA cycling, creating a "sawtooth" appearance, while the positive time period uses ensemble means from the 3-h free forecast period (1800-2100 UTC). Both temperature and wind show little difference in RMSD among all experiments during the free forecast, aside from a small degradation in RMSD of wind for NOSFC. Most of the notable differences occur in specific humidity. Experiment NOSFC errors are generally $0.5 \mathrm{~g} \mathrm{~kg}^{-1}$ higher than CNTL. Experiments denyCWOP and denyCWwnd are generally lowest in RMSD, though the differences are small, compared to CNTL. In terms of bias, there tends to be a model dry bias in moisture on the order of $0.5-1.0 \mathrm{~g} \mathrm{~kg}^{-1}$. There is also a high wind speed bias in the model, which may also be a reflection of the low speed bias of the nonconventional data, as discussed by Carlaw et al. (2015). 
RMSD Temp.

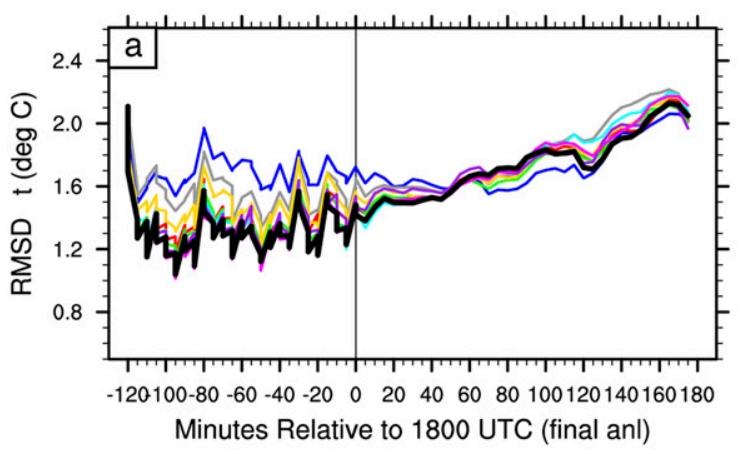

RMSD Spec. Hum.

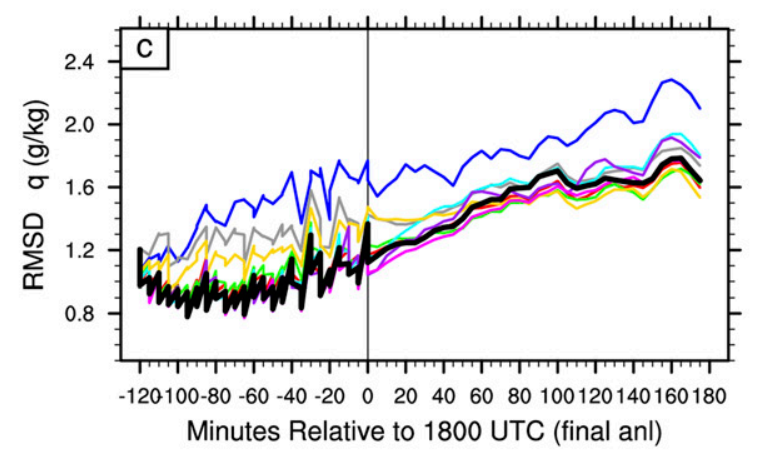

RMSD Wind

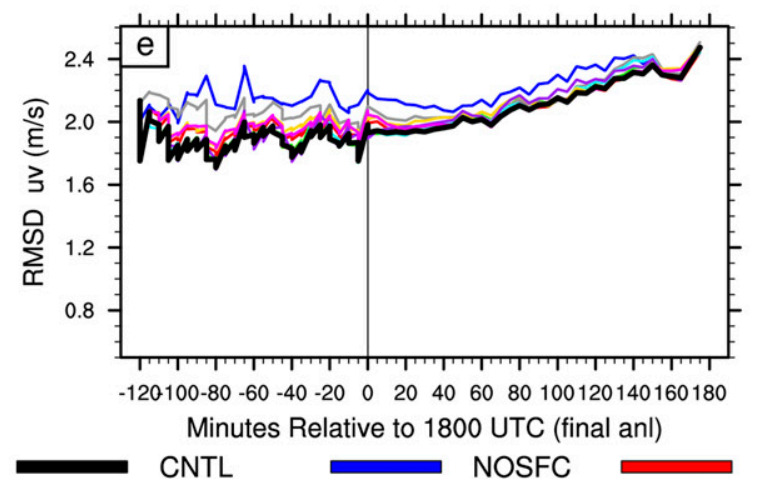

CNTL

NONEWSFC
NOSFC denyMISC
Bias ( fg-obs) Temp. Cat 5

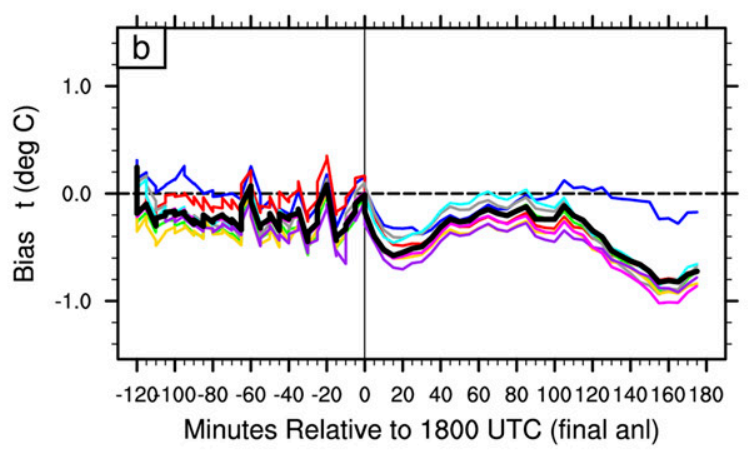

Bias ( fg-obs) Spec. Hum. Cat 5

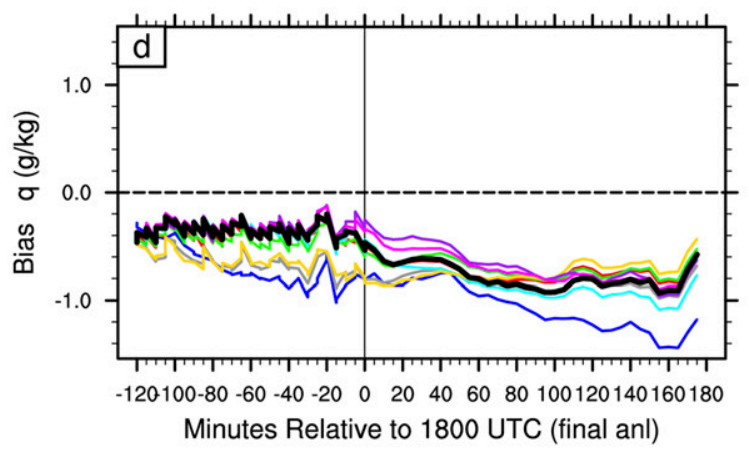

Bias ( $f g$-obs) Wind Cat 5

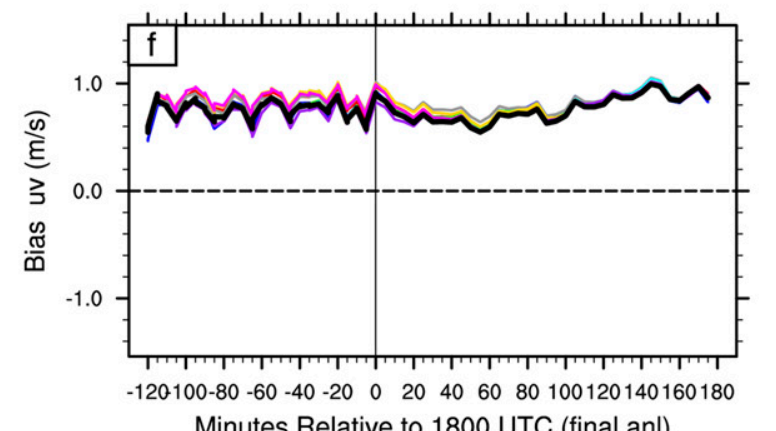

denyERNET

denyCW denyASOS

FIG. 17. Time series RMSD and bias (model minus observations) of ensemble mean for all experiments, plotted for (a),(b) temperature; (c),(d) dewpoint temperature; and (e),(f) wind. Note that the bias in (f) is wind magnitude bias only.

\section{d. Sensitivity to observation type}

Carlaw et al. (2015) found the majority of impact from nonconventional observations came from thermodynamic information. On the other hand, SS15 found slightly more impact on their CI forecasts from the wind information. To find out which information has a larger benefit for this case study, experiment denyCWwnd was conducted, where only the wind observations from CWOP and ERNET are denied but thermodynamic variables are still assimilated. Compared with denyCW, denyCWwnd matches much more closely with CNTL (Fig. 18), with only a minor reduction in ensemble probability within the first hour of the free forecast. Interestingly, the forecast of hail is improved in denyCWwnd for both 10- and 25-mm thresholds (Fig. 19). In fact, the $25-\mathrm{mm}$ NEP has improved by $10 \%$ and shows a maximum probability slightly closer to the significant hail reports in Denton. So in this case 
1810-1820 UTC
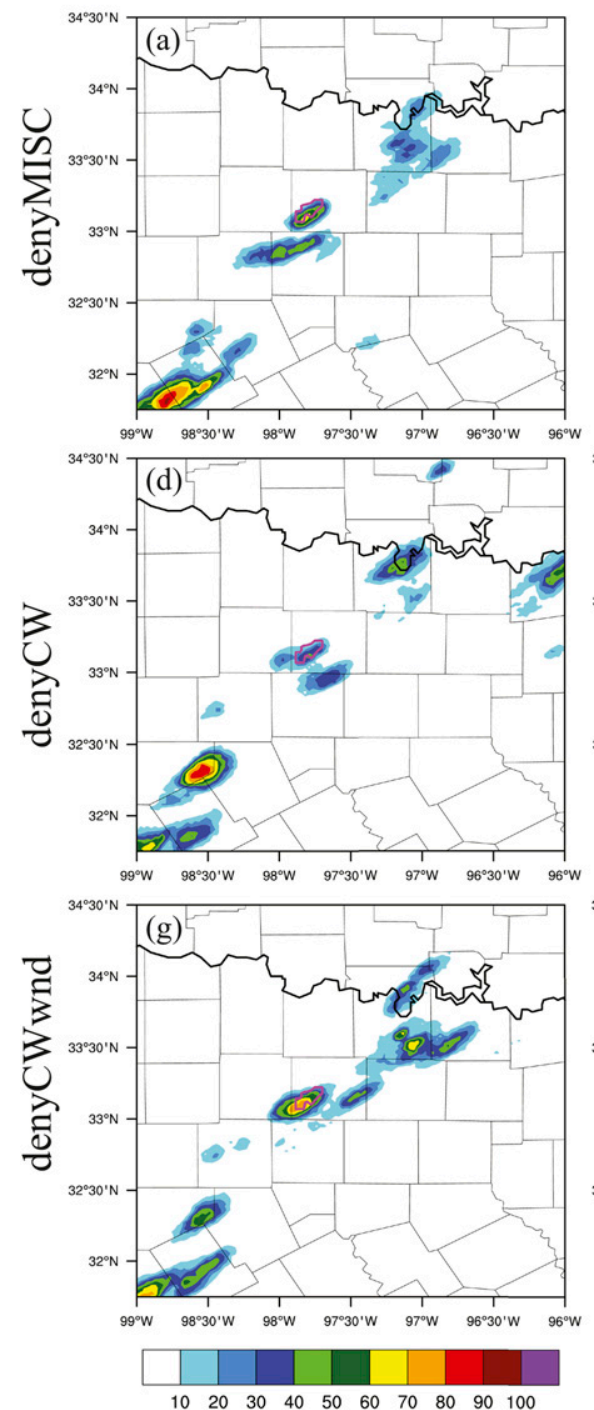

1825-1835 UTC
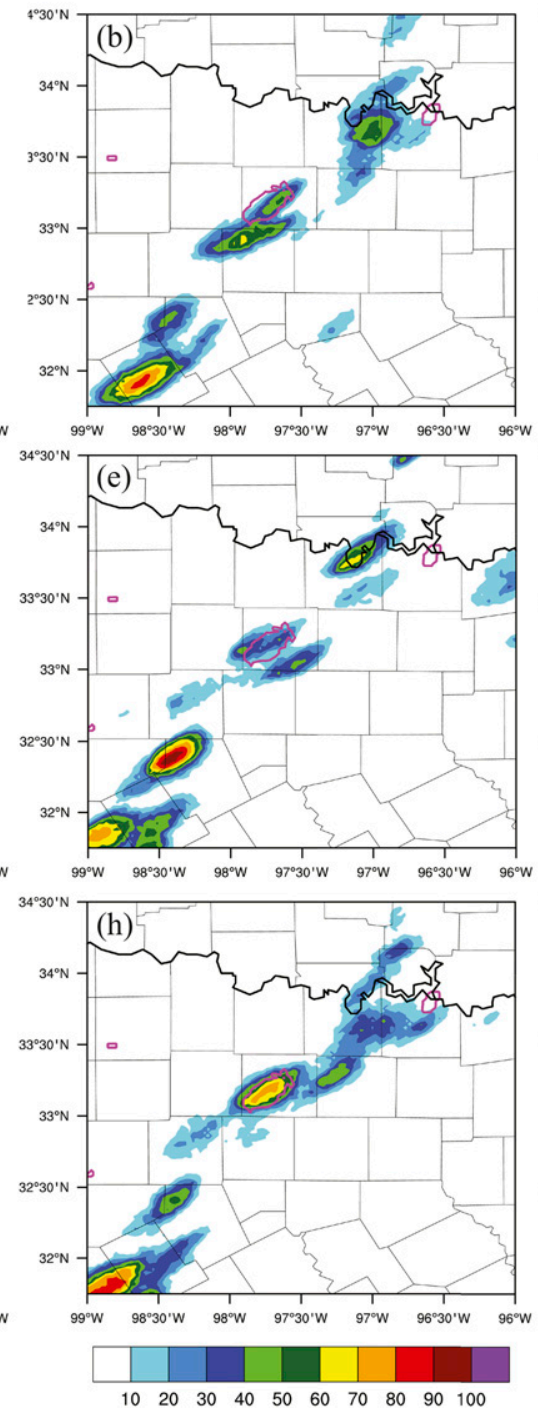

1840-1850 UTC
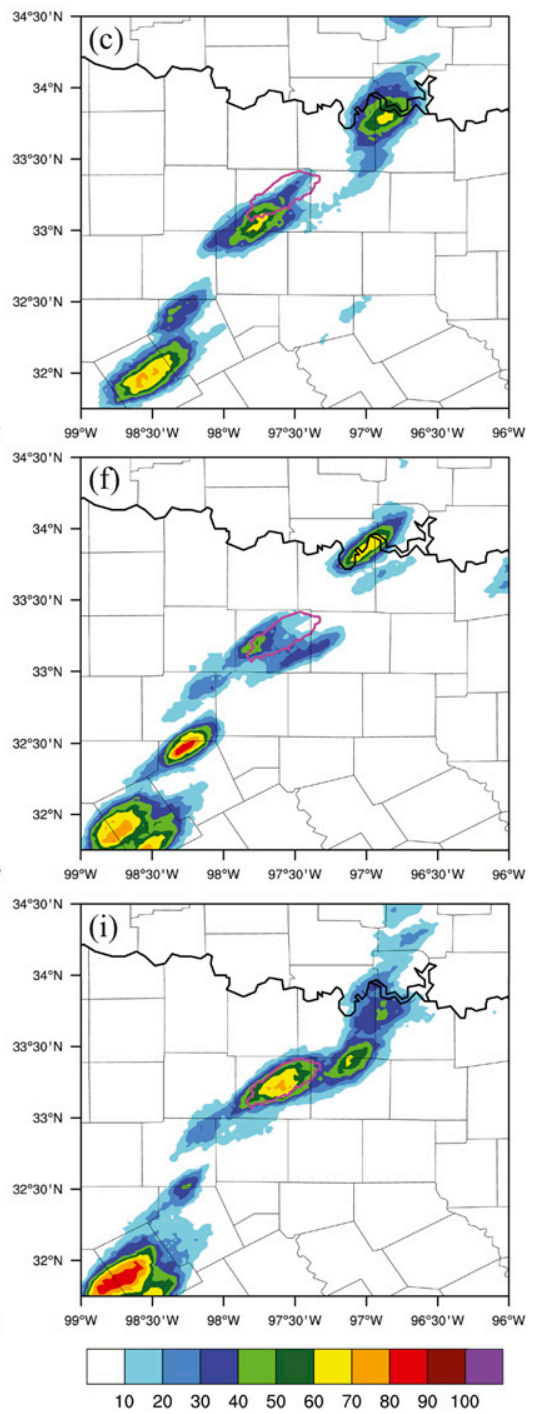

FIG. 18. As in Fig. 10, but for denial experiments (a)-(c) denyMISC, (d)-(f) denyCW, and (g)-(i) denyCWwnd.

study, it is clear that the thermodynamic information from the nonconventional datasets-specifically, moisture-is of greater importance than the wind information.

What could be the cause of wind observations slightly degrading the forecast? Previous studies focusing on nonconventional mesonet observations have mentioned low wind speed bias concerns of wind measurements, which is a potential source of degradation (Hilliker et al. 2010; Carlaw et al. 2015). Another source can be inferred from Fig. 17. Denying just the wind observations from CWOP and ERNET results in an almost negligible difference in the forecast RMSD of windan indication that the wind observations are not adding much information in an average sense. Additionally, the RMSD of specific humidity slightly improves over the CNTL just from denying wind observations. Their assimilation may only accumulate noise in the analysis from the large number of observations being assimilated. For example, at 1800 UTC, the variability of all CWOP and ERNET wind speed observations shown in Figs. $16 \mathrm{a}$ and $16 \mathrm{~b}$ is about $1.6 \mathrm{~m} \mathrm{~s}^{-1}$. The ensemble spread at each of these observation locations ranged from 0.25 to $0.6 \mathrm{~m} \mathrm{~s}^{-1}\left(0.42 \mathrm{~m} \mathrm{~s}^{-1}\right.$ average ) - lower as a result of the relatively homogeneous wind field where the majority of CWOP and ERNET observations are located. In other words, the variability of the ensemble wind is actually smaller than the variability of the nonconventional wind observations themselves, likely due to siting issues. 

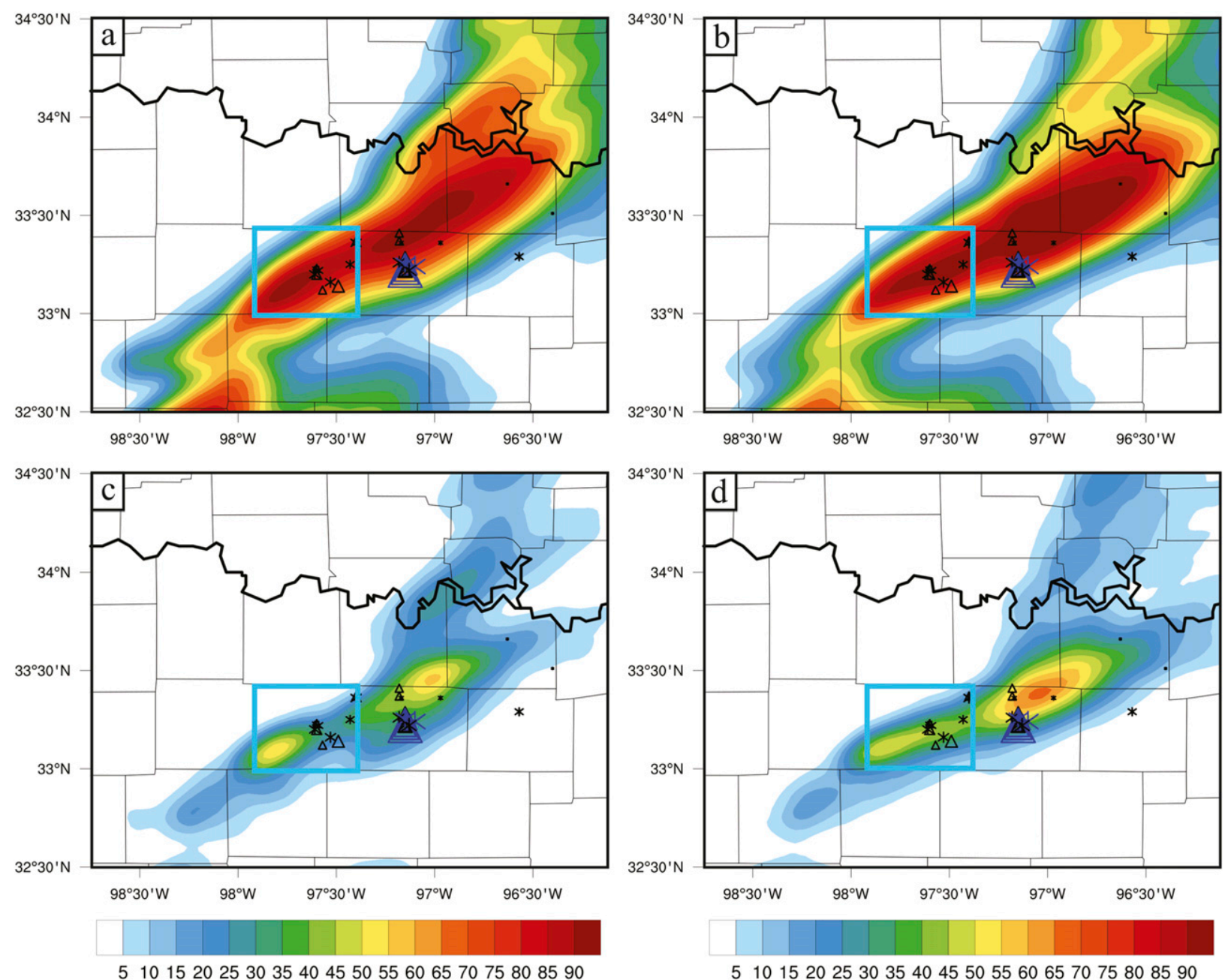

FIG. 19. As in Fig. 11, but comparing NEP of max hail size exceeding (a),(b) 10 and (c),(d) $25 \mathrm{~mm}$ for experiments (a),(c) CNTL and (b),(d) denyCWwnd.

\section{Summary and discussion}

While the number of studies assimilating surface observations in addition to radar observations has increased, there have been very few to examine the use of surface mesonet observations on forecasts of CI. Additionally, these mesonet surface observations are typically taken as one observation source. In this study, we examined the impacts of different systems of nonconventional surface observations on the forecast of CI for an extreme hail event in the DFW test bed (3 April 2014) using data denial experiments. The CNTL forecast captured location and timing of CI within $15 \mathrm{~km}$ and $15 \mathrm{~min}$, respectively, as well as produced hail forecast probability swaths with maxima in severe hail probabilities near the locations of the largest hail reports, giving the OSE credibility for examination of denial experiments. Our results indicated that while nonconventional data sources did not have a very large magnitude impact, compared with conventional surface observations, they still had an important contribution to the accurate prediction of $\mathrm{CI}$ and subsequent hail within the ensemble. Each nonconventional dataset contained observations from different locations that enhanced the moisture near the CI location, leading to a cumulative beneficial effect from all networks. These important observations were all located in advantageous areas just along the dryline, bringing to mind a key result of Tyndall and Horel (2013): "location, location, location." They found that observations located in data-sparse regions or in regions with sensitive local weather patterns (i.e., coastal regions) had the biggest impact. Ensemble sensitivity analyses (ESAs) can help reveal these advantageous sensitive areas where observations can have an impact, which can be used for observation targeting 
purposes (e.g., Ancell and Hakim 2007; Torn and Hakim 2008; Hill et al. 2016). In particular, Hill et al. (2016) performed an ESA on dryline forecasts of CI and found large sensitivity in thermodynamic variables upstream of the CI locations, particularly apparent in the dewpoint gradient magnitude along the dryline where CI occurs. Similarly, the most important observations in this study were found within the dryline gradient, in areas where observations were relatively sparse compared to the dense observations in the most populous parts of DFW. Additionally, high-moisture observations found upstream near the gradient (e.g., Fig. 16d) had a positive impact on the resulting $\mathrm{CI}$ and storm evolution forecast within CNTL.

The high-frequency assimilation of surface observations assisted in reducing moisture biases near the dryline that were prevalent in the model, similar to SS15. The ASOS and AWOS data largely constrained the dryline position and gradient strength, preventing the model from overmixing the dryline and causing the surface to be too dry in areas where CI occurred in reality. The addition of nonconventional observations helped to define the important small-scale features in drylines that are often the foci of CI. In this case, CWOP observations helped to define a small east-west kink in the dryline over Wise County, Texas, that allowed for the southerly flow within the moist regime to be more normal to the dryline, enhancing convergence and lift.

While the potential value of assimilating CWOP is intriguing, there are many issues that remain a challenge. Despite the positive result in CI, it was also clear that assimilating CWOP led to additional spurious convection, an indication that CWOP observations are noisy due to data quality issues. The siting concerns of CWOP prevent it from being optimally utilized. Nearly $10 \%$ of the CWOP observations in the domain of this study were flagged with having a reported elevation significantly different than the model terrain; some may be an inaccuracy in reported elevation (such as reporting in feet rather than meters), but others could be a misreported location. In their study assimilating dense pressure observations, Madaus et al. (2014) applied an "elevation comparison check" that rejected approximately $15 \%$ of their observations for having a difference of greater than $200 \mathrm{~m}$ in observed elevation, compared to the model terrain. While the GSI automatically handled these siting issues within its QC scheme, it still leaves some untapped potential into fully utilizing these nonconventional observations.

Despite the issues with nonconventional observations, this case study was still important in quantifying the value we can get from these surface observations in our DA systems. They truly can give us the small-scale information that is necessary to pinpoint the correct location for CI in a dryline case. The caveat is this is just one case study, though an important high-impact case. Many more cases need to be examined utilizing nonconventional observations, or perhaps a month-long quasi-real-time study. Additionally, biases over time of nonconventional networks should be examined and corrected, similar to the bias correction for surface pressure observations by Madaus et al. (2014).

Finally, this work lays the foundation for examining the application of the ensemble forecast sensitivity to observations (EFSO; Kalnay et al. 2012; Gasperoni and Wang 2015) on the convective scale. The EFSO can estimate impact from subsets of observations without the need for expensive data denial experiments, but is limited by the need for more complex localization methods to ensure accurate estimates (e.g., Gasperoni and Wang 2015). In future work, we plan on comparing estimates obtained by EFSO with different adaptive localization techniques to impact estimates obtained from data denial experiments performed in this work.

Acknowledgments. This project was supported by NOAA Awards NA16OAR4320115, NA16OAR4590236, and NA15OAR4590193. Archived observations for this study were provided through the Meteorological Data Assimilation Ingest System (MADIS). The authors acknowledge in particular Earth Networks, Global Science and Technology, and Oklahoma Mesonet for graciously providing observation data access. The Oklahoma Mesonet is a cooperative venture between Oklahoma State University and the University of Oklahoma and supported by the taxpayers of Oklahoma. The authors also thank Aaron Johnson and Yongming Wang for providing the assimilation system used in this work. Additionally, the authors thank Aaron Johnson, Samuel Degelia, Hristo Chipilski, and Yongming Wang for their valuable input throughout the duration of this research project. The computing for this project was performed at the OU Supercomputing Center for Education and Research (OSCER) at the University of Oklahoma (OU). This work is part of the first author's Ph.D. dissertation, and some of the work was presented during the AMS conference.

\section{REFERENCES}

Aksoy, A., D. C. Dowell, and C. Snyder, 2009: A multicase comparative assessment of the ensemble Kalman filter for assimilation of radar observations. Part I: Storm-scale analyses. Mon. Wea. Rev., 137, 1805-1824, https://doi.org/10.1175/ 2008MWR2691.1.

Ancell, B., and G. J. Hakim, 2007: Comparing adjoint- and ensemble-sensitivity analysis with applications to observation 
targeting. Mon. Wea. Rev., 135, 4117-4134, https://doi.org/ 10.1175/2007MWR1904.1.

_ C. C. F. Mass, and G. J. Hakim, 2011: Evaluation of surface analyses and forecasts with a multiscale ensemble Kalman filter in regions of complex terrain. Mon. Wea. Rev., 139, 20082024, https://doi.org/10.1175/2010MWR3612.1.

Andersson, E., A. Hollingsworth, G. Kelly, P. Lönnberg, J. Pailleux, and Z. Zhang, 1991: Global observing system experiments on operational statistical retrievals of satellite sounding data. Mon. Wea. Rev., 119, 1851-1865, https://doi.org/ 10.1175/1520-0493(1991)119<1851:GOSEOO > 2.0.CO;2.

Banacos, P. C., and D. M. Schultz, 2005: The use of moisture flux convergence in forecasting convective initiation: Historical and operational perspectives. Wea. Forecasting, 20, 351-366, https://doi.org/10.1175/WAF858.1.

Benjamin, S. G., B. D. Jamison, W. R. Moninger, S. R. Sahm, B. E. Schwartz, and T. W. Schlatter, 2010: Relative short-range forecast impact from aircraft, profiler, radiosonde, VAD, GPS-PW, METAR, and mesonet observations via the RUC hourly assimilation cycle. Mon. Wea. Rev., 138, 1319-1343, https://doi.org/10.1175/2009MWR3097.1.

Bosse, J., D. Oberholzer, M. Nelson, and R. Ware, 2012: Thermodynamic remote sensing of the boundary layer and above: A network approach. 16th Int. Symp. for the Advancement of Boundary-Layer Remote Sensing, Boulder, CO, CIRES/ NOAA, 2 pp.

Carlaw, L. B., J. A. Brotzge, and F. H. Carr, 2015: Investigating the impacts of assimilating surface observations on highresolution forecasts of the 15 May 2013 tornado event. Electron. J. Severe Storms Meteor., 10 (2), 1-34, http://ejssm.org/ ojs/index.php/ejssm/article/view/145/103.

Chadwick, R., 2014: Citizen Weather Observer Program. CWOP, accessed 8 June 2017, http://www.wxqa.com.

Chen, X., K. Zhao, J. Sun, B. Zhou, and W.-C. Lee, 2016: Assimilating surface observations in a four-dimensional variational Doppler radar data assimilation system to improve the analysis and forecast of a squall line case. Adv. Atmos. Sci., 33, 1106-1119, https://doi.org/10.1007/s00376-016-5290-0.

Chou, M.-D., and M. J. Suarez, 1999: A solar radiation parameterization for atmospheric studies. NASA Tech. Rep. NASA/ TM-1999-104606, Vol. 15, 40 pp, https://ntrs.nasa.gov/archive/ nasa/casi.ntrs.nasa.gov/19990060930.pdf.

Coniglio, M. C., J. Correia, P. T. Marsh, and F. Kong, 2013: Verification of convection-allowing WRF Model forecasts of the planetary boundary layer using sounding observations. Wea. Forecasting, 28, 842-862, https://doi.org/10.1175/WAF-D-12-00103.1.

— S. M. Hitchcock, and K. H. Knopfmeier, 2016: Impact of assimilating preconvective upsonde observations on short-term forecasts of convection observed during MPEX. Mon. Wea. Rev., 144, 4301-4325, https://doi.org/10.1175/MWR-D-16-0091.1.

Dabberdt, W. F., and Coauthors, 2005: Multifunctional mesoscale observing networks. Bull. Amer. Meteor. Soc., 86, 961-982, https://doi.org/10.1175/BAMS-86-7-961.

Dahlia, J., 2013: The national mesonet program: Filling in the gaps. Weatherwise, 66, 26-33, https://doi.org/10.1080/00431672.2013.800418.

Degelia, S., X. Wang, D. Stensrud, and A. Johnson, 2018: Understanding the impact of radar and in situ observations on the prediction of a nocturnal convection initiation event on 25 June 2013 using an ensemble-based multiscale data assimilation system. Mon. Wea. Rev., 146, 1837-1859, https://doi.org/10.1175/MWR-D-17-0128.1.

Earth Networks, 2017: Weather: Get smart about the weather. Earth Networks, accessed 1 July 2017, https://www.earthnetworks.com/ why-us/networks/weather/.
Elmore, K. L., Z. L. Flamig, V. Lakshmanan, B. T. Kaney, V. Farmer, H. D. Reeves, and L. P. Rothfusz, 2014: MPING: Crowd-sourcing weather reports for research. Bull. Amer. Meteor. Soc., 95, 1335-1342, https://doi.org/10.1175/BAMS-D13-00014.1.

Gaspari, G., and S. E. Cohn, 1999: Construction of correlation functions in two and three dimensions. Quart. J. Roy. Meteor. Soc., 125, 723-757, https://doi.org/10.1002/qj.49712555417.

Gasperoni, N. A., and X. Wang, 2015: Adaptive localization for the ensemble-based observation impact estimate using regression confidence factors. Mon. Wea. Rev., 143, 1981-2000, https:// doi.org/10.1175/MWR-D-14-00272.1.

Grell, G. A., and D. Dévényi, 2002: A generalized approach to parameterizing convection combining ensemble and data assimilation techniques. Geophys. Res. Lett., 29, 1693, https:// doi.org/10.1029/2002GL015311.

__ and S. R. Freitas, 2014: A scale and aerosol aware stochastic convective parameterization for weather and air quality modeling. Atmos. Chem. Phys., 14, 5233-5250, https://doi.org/ 10.5194/acp-14-5233-2014.

Hane, C. E., H. B. Bluestein, T. M. Crawford, M. E. Baldwin, and R. M. Rabin, 1997: Severe thunderstorm development in relation to along-dryline variability: A case study. Mon. Wea. Rev., 125, 231-251, https://doi.org/10.1175/15200493(1997)125<0231:STDIRT>2.0.CO;2.

- R. M. Rabin, T. M. Crawford, H. B. Bluestein, and M. E. Baldwin, 2002: A case study of severe storm development along a dryline within a synoptically active environment. Part II: Multiple boundaries and convective initiation. Mon. Wea. Rev., 130, 900-920, https://doi.org/10.1175/1520-0493(2002)130<0900: ACSOSS $>2.0 . \mathrm{CO} ; 2$.

Heppner, P., 2013: Building a national network of mobile platforms for weather detection. 29th Conf. on Environmental Information Processing Technologies, Austin, TX, Amer. Meteor. Soc., 5.8, https://ams.confex.com/ams/93Annual/ webprogram/Paper222600.html.

Hill, A. J., C. C. Weiss, and B. C. Ancell, 2016: Ensemble sensitivity analysis for mesoscale forecasts of dryline convection initiation. Mon. Wea. Rev., 144, 4161-4182, https://doi.org/10.1175/ MWR-D-15-0338.1.

Hilliker, J. L., G. Akasapu, and G. S. Young, 2010: Assessing the short-term forecast capability of nonstandardized surface observations using the National Digital Forecast Database (NDFD). J. Appl. Meteor. Climatol., 49, 1397-1411, https:// doi.org/10.1175/2010JAMC2137.1.

Houtekamer, P. L., and H. L. Mitchell, 1998: Data assimilation using an ensemble Kalman filter technique. Mon. Wea. Rev., 126, 796-811, https://doi.org/10.1175/1520-0493(1998)126<0796: DAUAEK $>2.0 . \mathrm{CO} ; 2$.

__, and —_, 2001: A sequential ensemble Kalman filter for atmospheric data assimilation. Mon. Wea. Rev., 129, 123-137, https://doi.org/10.1175/1520-0493(2001)129<0123: ASEKFF>2.0.CO;2.

Iacono, M. J., J. S. Delamere, E. J. Mlawer, M. W. Shephard, S. A. Clough, and W. D. Collins, 2008: Radiative forcing by longlived greenhouse gases: Calculations with the AER radiative transfer models. J. Geophys. Res., 113, D13103, https://doi.org/ 10.1029/2008JD009944.

Janjić, Z. I., 1994: The step-mountain eta coordinate model: Further developments of the convection, viscous sublayer, and turbulence closure schemes. Mon. Wea. Rev., 122, 927-945, https://doi.org/10.1175/1520-0493(1994)122<0927: TSMECM > 2.0.CO;2. 
Johnson, A., and X. Wang, 2017: Design and implementation of a GSI-based convection-allowing ensemble data assimilation and forecast system for the PECAN field experiment. Part I: Optimal configurations for nocturnal convection prediction using retrospective cases. Wea. Forecasting, 32, 289-315, https:// doi.org/10.1175/WAF-D-16-0102.1.

,-- J. R. Carley, L. J. Wicker, and C. Karstens, 2015: A comparison of multiscale GSI-based EnKF and 3DVar data assimilation using radar and conventional observations for midlatitude convective-scale precipitation forecasts. Mon Wea. Rev., 143, 3087-3108, https://doi.org/10.1175/MWR-D14-00345.1.

Kain, J. S., 2004: The Kain-Fritsch convective parameterization: An update. J. Appl. Meteor., 43, 170-181, https://doi.org/ 10.1175/1520-0450(2004)043<0170:TKCPAU>2.0.CO;2.

Kalnay, E., Y. Ota, T. Miyoshi, and J. Liu, 2012: A simpler formulation of forecast sensitivity to observations: Application to ensemble Kalman filters. Tellus, 64A, 18462, https://oi.org/ 10.3402/tellusa.v64i0.18462.

Keyser, D., 2017: PREPBUFR processing at NCEP. NCEP, accessed 23 June 2017, http://www.emc.ncep.noaa.gov/mmb/ data_processing/prepbufr.doc/document.htm.

Kutty, G., and X. Wang, 2015: A comparison of the impacts of radiosonde and AMSU radiance observations in GSI based 3DEnsVar and 3DVar data assimilation systems for NCEP GFS. Adv. Meteor., 2015, 280546, https://doi.org/10.1155/2015/ 280546.

Lakshmanan, V., T. Smith, G. Stumpf, and K. Hondl, 2007: The Warning Decision Support System-Integrated Information. Wea. Forecasting, 22, 596-612, https://doi.org/ 10.1175/WAF1009.1.

Liu, H., and M. Xue, 2008: Prediction of convective initiation and storm evolution on 12 June 2002 during IHOP_2002. Part I Control simulation and sensitivity experiments. Mon. Wea. Rev., 136, 2261-2282, https://doi.org/10.1175/2007MWR2161.1.

Madaus, L. E., and G. J. Hakim, 2016: Observable surface anomalies preceding simulated isolated convective initiation. Mon. Wea. Rev., 144, 2265-2284, https://doi.org/10.1175/MWR-D 15-0332.1.

— and - 2017: Constraining ensemble forecasts of discrete convective initiation with surface observations. Mon. Wea Rev., 145, 2597-2610, https://doi.org/10.1175/MWR-D-160395.1.

-,- , and C. F. Mass, 2014: Utility of dense pressure observations for improving mesoscale analyses and forecasts. Mon. Wea. Rev., 142, 2398-2413, https://doi.org/10.1175/ MWR-D-13-00269.1.

Massart, S., B. Pajot, A. Piacentini, and O. Pannekoucke, 2010: On the merits of using a 3D-FGAT assimilation scheme with an outer loop for atmospheric situations governed by transport. Mon. Wea. Rev., 138, 4509-4522, https://doi.org/ 10.1175/2010MWR3237.1.

McLaughlin, D., and Coauthors, 2009: Short-wavelength technology and the potential for distributed networks of small radar systems. Bull. Amer. Meteor. Soc., 90, 1797-1818, https://doi.org/ 10.1175/2009BAMS2507.1.

McPherson, R. A., and Coauthors, 2007: Statewide monitoring of the mesoscale environment: A technical update on the Oklahoma Mesonet. J. Atmos. Oceanic Technol., 24, 301-321, https:// doi.org/10.1175/JTECH1976.1.

Miller, P. A., M. F. Barth, and L. A. Benjamin, 2005: An update on MADIS observation ingest, integration, quality control, and distribution capabilities. 21st Int. Conf. on Interactive
Information Processing Systems (IIPS) for Meteorology, Oceanography, and Hydrology, San Diego, CA, Amer. Meteor. Soc., J7.12, https://ams.confex.com/ams/Annual2005/ techprogram/paper_86703.htm.

Moninger, W. R., R. D. Mamrosh, and P. M. Pauley, 2003: Automated meteorological reports from commercial aircraft. Bull. Amer. Meteor. Soc., 84, 203-216, https://doi.org/10.1175/ BAMS-84-2-203.

Nakanishi, M., and H. Niino, 2009: Development of an improved turbulent closure model for the atmospheric boundary layer. J. Meteor. Soc. Japan, 87, 895-912, https://doi.org/10.2151/jmsj.87.895.

NCDC, 2014: Storm Data. Vol. 56, No. 4, 652 pp.

NRC, 2009: Observing Weather and Climate from the Ground Up: A Nationwide Network of Networks. The National Academies Press, $250 \mathrm{pp}$.

2012: Urban Meteorology: Forecasting, Monitoring, and Meeting Users' Needs. The National Academies Press, 190 pp.

Pu, Z., H. Zhang, and J. Anderson, 2013: Ensemble Kalman filter assimilation of near-surface observations over complex terrain: Comparison with $3 \mathrm{DVAR}$ for short-range forecasts. Tellus, 65A, 19620, https://doi.org/10.3402/tellusa.v65i0.19620.

Roberts, R. D., and S. Rutledge, 2003: Nowcasting storm initiation and growth using GOES-8 and WSR-88D data. Wea. Forecasting, 18, 562-584, https://doi.org/10.1175/1520-0434(2003)018<0562: NSIAGU $>2.0 . \mathrm{CO} ; 2$.

Schenkman, A., M. Xue, A. Shapiro, K. Brewster, and J. Gao, 2011a: The analysis and prediction of the 8-9 May 2007 Oklahoma tornadic mesoscale convective system by assimilating WSR-88D and CASA radar data using 3DVAR. Mon. Wea. Rev., 139, 224-246, https://doi.org/10.1175/2010MWR3336.1.

,,,$--- \ldots$, and,$- 2011 \mathrm{~b}$ : Impact of CASA radar and Oklahoma Mesonet data assimilation on the analysis and prediction of tornadic mesovortices in an MCS. Mon. Wea. Rev., 139, 3422-3445, https://doi.org/10.1175/MWR-D-10-05051.1.

Schroeder, J. L., W. S. Burgett, K. B. Haynie, I. Sonmez, G. D. Skwira, A. L. Doggett, and J. W. Lipe, 2005: The West Texas Mesonet: A technical overview. J. Atmos. Oceanic Technol., 22, 211222, https://doi.org/10.1175/JTECH-1690.1.

Schwartz, C. S., and Coauthors, 2010: Toward improved convectionallowing ensembles: Model physics sensitivities and optimizing probabilistic guidance with small ensemble membership. Wea. Forecasting, 25, 263-280, https://doi.org/10.1175/ 2009WAF2222267.1.

Singh, R., S. P. Ojha, C. M. Kishtawal, and P. K. Pal, 2014: Impact of various observing systems on weather analysis and forecast over the Indian region. J. Geophys. Res. Atmos., 119, 10232 10 246, https://doi.org/10.1002/2014JD021890.

Skamarock, W. C., and J. B. Klemp, 2008: A time-split nonhydrostatic atmospheric model for weather research and forecasting applications. J. Comput. Phys., 227, 3465-3485, https://doi.org/10.1016/ j.jcp.2007.01.037.

Snook, N., M. Xue, and Y. Jung, 2015: Multiscale EnKF assimilation of radar and conventional observations and ensemble forecasting for a tornadic mesoscale convective system. Mon. Wea. Rev., 143, 1035-1057, https://doi.org/10.1175/MWR-D-13-00262.1.

Sobash, R. A., and D. J. Stensrud, 2013: The impact of covariance localization for radar data on EnKF analyses of a developing MCS: Observing system simulation experiments. Mon. Wea. Rev., 141, 3691-3709, https://doi.org/10.1175/MWR-D-12-00203.1. , and - 2015: Assimilating surface mesonet observations with the EnKF to improve ensemble forecasts of convection initiation on 29 May 2012. Mon. Wea. Rev., 143, 3700-3725, https://doi.org/10.1175/MWR-D-14-00126.1. 
Tewari, M., and Coauthors, 2004: Implementation and verification of the unified Noah land surface model in the WRF Model. 20th Conf. on Weather Analysis and Forecasting/ 16th Conf. on Numerical Weather Prediction, Seattle, WA, Amer. Meteor. Soc., 14.2a, https://ams.confex.com/ams/ 84Annual/techprogram/paper_69061.htm.

Thompson, G., P. R. Field, R. M. Rasmussen, and W. D. Hall, 2008: Explicit forecasts of winter precipitation using an improved bulk microphysics scheme. Part II: Implementation of a new snow parameterization. Mon. Wea. Rev., 136, 5095-5115, https://doi.org/10.1175/2008MWR2387.1.

Thompson, R., and J. Hart, 2017: SPC experimental sounding analysis system. NOAA/Storm Prediction Center, accessed 16 June 2017, http://www.spc.noaa.gov/exper/soundings/help/index.html.

Tong, M., and M. Xue, 2005: Ensemble Kalman filter assimilation of Doppler radar data with a compressible nonhydrostatic model: OSS experiments. Mon. Wea. Rev., 133, 1789-1807, https://doi.org/10.1175/MWR2898.1.

Torn, R. D., and G. J. Hakim, 2008: Ensemble-based sensitivity analysis. Mon. Wea. Rev., 136, 663-677, https://doi.org/10.1175/ 2007MWR2132.1.

Tyndall, D. P., and J. D. Horel, 2013: Impacts of mesonet observations on meteorological surface analyses. Wea. Forecasting, 28, 254-269, https://doi.org/10.1175/WAF-D-12-00027.1.

Understory Weather, 2015: Understory sensor data: Weather monitoring networks accurately measuring hail and wind. Understory, white paper, http://understoryweather.com/business-solutions/ stem-education-programs-weather-analytics/.

van Zomeren, J., and A. van Delden, 2007: Vertically integrated moisture flux convergence as a predictor of thunderstorms. Atmos. Res., 83, 435-445, https://doi.org/10.1016/j.atmosres.2005.08.015.

Wang, Y., and X. Wang, 2017: Direct assimilation of radar reflectivity without tangent linear and adjoint of the nonlinear observation operator in the GSI-based EnVar system: Methodology and experiment with the 8 May 2003 Oklahoma City tornadic supercell. Mon. Wea. Rev., 145, 1447-1471, https:// doi.org/10.1175/MWR-D-16-0231.1.

WeatherFlow, 2017: Sodar and lidar. WeatherFlow, accessed 8 June 2017, http://weatherflow.com/professional-services/ wind-energy/sodar-and-lidar/.
Weckwerth, T. M., 2000: The effect of small-scale moisture variability on thunderstorm initiation. Mon. Wea. Rev., 128, 4017-4030, https://doi.org/10.1175/1520-0493(2000)129<4017: TEOSSM $>2.0 . \mathrm{CO} ; 2$.

— and motivation for IHOP_2002. Mon. Wea. Rev., 134, 5-22, https://doi.org/10.1175/MWR3067.1.

- and Coauthors, 2004: An overview of the International $\mathrm{H}_{2} \mathrm{O}$ Project (IHOP_2002) and some preliminary highlights. Bull. Amer. Meteor. Soc., 85, 253-278, https://doi.org/10.1175/BAMS-85-2-253.

Whitaker, J. S., and T. M. Hamill, 2002: Ensemble data assimilation without perturbed observations. Mon. Wea. Rev., 130, 1913-1924, https://doi.org/10.1175/1520-0493(2002)130<1913: EDAWPO $>2.0 . \mathrm{CO} ; 2$.

— errors in ensemble data assimilation. Mon. Wea. Rev., 140, 3078-3089, https://doi.org/10.1175/MWR-D-11-00276.1.

Xue, M., and W. J. Martin, 2006a: A high-resolution modeling study of the 24 May 2002 dryline case during IHOP. Part I: Numerical simulation and general evolution of the dryline and convection. Mon. Wea. Rev., 134, 149-171, https://doi.org/ 10.1175/MWR3071.1.

— , and 2006b: A high-resolution modeling study of the 24 May 2002 dryline case during IHOP. Part II: Horizontal convective rolls and convective initiation. Mon. Wea. Rev., 134, 172-191, https://doi.org/10.1175/MWR3072.1.

Zapotocny, T. H., W. P. Menzel, J. P. Nelson, and J. A. Jung, 2002: An impact study of five remotely sensed and five in situ data types in the Eta Data Assimilation System. Wea. Forecasting, 17, 263-285, https://doi.org/10.1175/1520-0434(2002)017<0263: AISOFR $>2.0 . \mathrm{CO} ; 2$.

_ J. A. Jung, J. F. Le Marshall, and R. E. Treadon, 2007: A twoseason impact study of satellite and in situ data in the NCEP Global Data Assimilation System. Wea. Forecasting, 22, 887909, https://doi.org/10.1175/WAF1025.1.

Zhang, X., Y. Luo, Q. Wan, W. Ding, and J. Sun, 2016: Impact of assimilating wind profiling radar observations on convectionpermitting quantitative precipitation forecasts during SCMREX. Wea. Forecasting, 31, 1271-1292, https://doi.org/10.1175/ WAF-D-15-0156.1. 